Revista General de Información y Documentación ISSN: 1132-1873

http://dx.doi.org/10.5209/RGID.60812

\title{
La Biblioteca Membrado: lecturas de una familia bajoaragonesa en el siglo XVIII y primera mitad del XIX
}

\author{
María Dolores Gimeno Puyol ${ }^{1}$
}

Recibido: 18 de diciembre 2017 / Aceptado: 14 de marzo de 2018

Resumen. Sucesivas generaciones de los Membrado, una familia hacendada de la localidad bajoaragonesa de Belmonte, reunieron una biblioteca que actualmente conserva 106 títulos. Este artículo realiza su catalogación y su análisis. Por un lado, se revisa su proceso de configuración a lo largo del siglo XVIII y primera mitad del XIX, incidiendo en los modos de obtención o procedencia de los libros y en algunas prácticas lectoras, así como su intencionalidad. Por otro lado, se clasifican y revisan los temas presentes, que describen un ciclo de lecturas desde el aprendizaje de las primeras letras a los estudios eclesiásticos o jurídicos junto a las posteriores de tipo profesional y práctico o encaminadas al ocio. Esa morfología y otros aspectos materiales (autores, lugares de edición, lenguas, formatos) informan del universo mental de sus lectores, aportan datos sobre un entorno erudito en el ámbito rural de la época y destacan el valor del libro en la formación personal y el ascenso social.

Palabras clave: Biblioteca; Usos del libro; Lectura; Siglo XVIII; Siglo XIX, Bajo Aragón.

\section{[en] The Membrado Library: readings of a Bajoaragonese family in the 18th century and the first half of the 19th century}

\begin{abstract}
Successive generations of the Membrado, a landed family from the Bajoaragonese town of Belmonte established a library that currently holds 106 titles. This article carries out its cataloguing and analysis. On the one hand, its configuration process throughout the 18th century and the first half of the 19th century is revised, focusing on the ways the ways the books were obtained or their provenance, and also examines some reading practices, as well as their intentionality. On the other hand, the present subjects are classified and reviewed, pointing out a cycle of readings from the learning of the first letters to the ecclesiastical or legal studies together with later books dedicated to leisure and professional or practical purposes. This morphology and other material aspects (authors, editing places, languages, formats) reveal the mental universe of its readers, provide data on a scholarly environment in rural areas at that time and highlight the value of the book in personal formation and social promotion.
\end{abstract}

Keywords: Library; Uses of the book; Reading; $18^{\text {th }}$ century; $19^{\text {th }}$ century; Bajo Aragón.

1 Universitat Rovira i Virgili. Departament de Filologies Romàniques

E-mail: mariadolores.gimeno@urv.cat 
Sumario. 1. Introducción; 2. El proceso de configuración; 3. Características del fondo; 4. Conclusiones; 5. Catálogo de la Biblioteca Membrado; 6. Referencias bibliográficas.

Cómo citar: Gimeno Puyol, M. D. (2018) La Biblioteca Membrado: lecturas de una familia bajoaragonesa en el siglo XVIII y primera mitad del XIX, en Revista General de Información y Documentación 28 (1), 243-273.

\section{Introducción}

La familia Membrado, que residió en la localidad bajoaragonesa de Belmonte de San José —Bellmunt del Mesquí según el topónimo autóctono - desde mediados del siglo XVII hasta el primer tercio del XX, reunió en ese tiempo y lugar una destacada colección de libros. Se da la feliz y poco frecuente circunstancia de que se conserva aún en la misma casa familiar, actualmente cuidada por un descendiente suyo, Ramón Mur Gimeno, quien la ha dividido en dos: la "Biblioteca del cura Membrado", con algo más de un centenar de ediciones y manuscritos desde el siglo XVI hasta mediados del XIX, y la "Biblioteca de Juan Pío Membrado", con 127 títulos de la segunda mitad del XIX y principios del XX, adquiridos por el último miembro de la saga. ${ }^{2}$ La distinción obedece, pues, a la diferencia cronológica y a la manera o intención en la reunión de cada una, biblioteca "familiar" la primera y "personal” la segunda.

Este estudio aborda la primera, la cual, fue formada por miembros de sucesivas generaciones, según se verá, de modo que puede comportar cierta heterogeneidad y resultar sobrevenido su designio de constituirse como tal. Así pues, a partir del análisis concreto de los títulos reunidos, de los ejemplares y de las marcas presentes en ellos, interesa, por un lado, rastrear su proceso de formación: procedimientos y circunstancias de adquisición, circuitos de lectores, fondos personales identificados...; por otro, caracterizar su morfología temáticocronológica, además de las lenguas presentes, la procedencia autorial y editorial y algunos elementos de bibliografía material. Esta doble dirección, articulada en sendos apartados, se vinculará a su condición de biblioteca particular, fruto de las inquietudes y necesidades personales, culturales o profesionales de sus distintos usuarios/poseedores, con el objetivo de analizar tanto aspectos ideológicos intereses e inclinaciones de aquellos- como otros más coyunturales, es decir, los usos concretos de lectura y modos de difusión textual y la posesión del libro como vía de acceso al saber — asociada sobre todo a los estudios- y, subsiguientemente, a una posición social en la comunidad de origen o fuera de ella. Todo ello se considerará en su contexto espacio-temporal, alejado de las bibliotecas institucionales que comenzaron a florecer en el siglo XVIII, antes de existir infraestructuras educativas y una red pública de bibliotecas, para calibrar su importancia. Su identificación y catalogación detallada, que se ofrecerá a

Mur Gimeno, además de confeccionar los respectivos inventarios, ha restaurado algunos ejemplares y ha repuesto mediante el mercado anticuario títulos que, según se desprende de su obra escrita, leyó o poseyó Juan Pío Membrado como el diccionario completo de Madoz. 
continuación, constituye un documento necesario y valioso, base de la anterior interpretación.

\section{El proceso de configuración}

La Biblioteca Membrado alberga actualmente 106 títulos: 99 impresos, algunos con más de un volumen o edición, y 7 textos manuscritos. ${ }^{3}$ No existe ningún inventario contemporáneo a su formación que certifique la existencia de un corpus determinado, aunque parece conservar con bastante integridad los libros que atesoraron los Membrado ya que no constan noticias de desmembración, ventas o expolios ni de daños naturales o bélicos. Pudieron incidir de manera puntual algunas prácticas como donaciones y apropiaciones particulares y préstamos no devueltos o pérdidas, igual que se observan deterioros en varios ejemplares. Asimismo, faltan volúmenes en algunas obras conformadas por varios.

Su configuración se realizó de modo progresivo, a lo largo del tiempo y a cargo de individuos de diferentes generaciones hasta llegar al cura Mariano Membrado, por lo que, aunque este fuese su depositario final, parece adecuado denominarla con el apellido familiar. No debió de comenzarla Juan, el fundador de la saga, quien junto a su hermano Pedro pudo comprar fincas y propiedades rústicas en la comarca gracias al negocio de compra-venta de ganados, aunque con el tiempo se estableció por su cuenta en Belmonte, donde casó con Esperanza Sabater el 29 de mayo de 1656 y tuvo tres hijos: Pedro (1659), Ana Petronila (1665) y Joseph (1668-1743). ${ }^{4}$ La casona que este último, su heredero, mandó construir en 1724 en la plaza mayor evidenciaba la voluntad de asentar la dinastía, mientras que los hijos de este personificaban la obtención del poder local: el primogénito Matías Membrado Bayod (1705-1775) como alcalde y Joseph como párroco. ${ }^{5}$

Más lectora fue la siguiente generación, que extendió su poder más allá de Belmonte al hilo de los estudios. Se introdujo en el ámbito regional con Matías Membrado Bosque (1739-1794), un tiempo abogado en Zaragoza y Decano de su colegio profesional (Mur Gimeno, 1990: 32-34). Fueron nuevamente alcaldes locales su hijo Juan Pío Membrado Latorre (1783-1855) y su nieto Joaquín Membrado Soro (1810-1855), quien representa la cima del poder familiar junto a sus hermanos: Mariano (1808-1865), párroco belmontino, y Ramón (1816-1865), abogado, diputado por Teruel y gobernador civil de la provincia. Aunque la saga se extingue con el siguiente sucesor, el mencionado Juan Pío Membrado Ejerique

3 El inventario de la "Biblioteca del cura Membrado" (Mur Gimeno, s. d.) consta de 105 asientos, siendo los $\mathrm{n}^{\circ}$ 99, 100 y 102 cuadernos de contabilidad o anotaciones jurídicas, que excluyo de mi catalogación por considerarlos material propio del archivo, pero añado algunos títulos de la "Biblioteca de Juan Pío Membrado" por sus fechas u otras razones; no he localizado el $n^{0} 105$ : “Apuntes, devocionario con un via crucis de 15 estaciones... Belmonte, siglo XVIII”.

4 Tomo estas fechas y las que siguen de Mur Gimeno (1990), quien las ha obtenido de los libros parroquiales de Belmonte.

5 Según reza la inscripción en la fachada principal, la casona se inició en 1724; y en un ventanal de forja se lee “Soy de Matías Membrado. 1743”. La construcción fue contemporánea a la de la iglesia parroquial, que ostenta en su fachada la fecha de 1742, obra del arquitecto Sastruz, vecino de Belmonte (Madoz, 1846: 132), quien pudo asesorar a los Membrado. 
(1851-1923), destacada figura del regeneracionismo aragonés, otro licenciado en Derecho en Zaragoza, que murió soltero y sin descendencia.

Los títulos universitarios contribuyeron, sin duda, a la consolidación de la dinastía, aportando capacitación profesional, poder y prestigio, más si cabe en un entorno donde las tasas de analfabetismo eran muy elevadas. ${ }^{6}$ Este proceso lo rubricaron los enlaces matrimoniales con familias hacendadas vecinas. En efecto, una buena parte de los libros conservados están relacionados con esos estudios laicos o eclesiásticos completados, cuyas fechas de edición van paralelas al devenir de los Membrado: en torno a la mitad de los títulos - 51 — son del siglo XVIII y más de una cuarta parte de la primera mitad del siglo XIX. No es desdeñable la presencia de 15 ediciones del XVII, mientras es más testimonial la de tres del XVI, anteriores al establecimiento en Belmonte.

Tabla 1. Clasificación cronológica de la Biblioteca Membrado

\begin{tabular}{|l|r|r|r|r|}
\hline Siglos de edición & Impresos & Mss. & Total & \% \\
\hline XVI & 3 & & & 2,8 \\
\hline XVII & 15 & & & 14,1 \\
\hline XVIII & 50 & 4 & 54 & 50,9 \\
\hline XIX & 30 & & & 28,3 \\
\hline Sin identificar & 1 & 3 & 4 & 3,7 \\
\hline & 99 & 7 & 106 & \\
\hline
\end{tabular}

Las indicaciones de propiedad en varios ejemplares son evidencias aún más directas, puesto que informan de las adquisiciones realizadas por distintos miembros de la familia, directa o política, a la vez que revelan su conciencia de poseer fondos personales. Algunas son esporádicas, como la de Joseph Membrado, el primero en cursar estudios superiores y párroco de Belmonte — según se ha dicho-, que aparece en las Artificiosae Orationis sive Rhetoricarum Institutionum Epitome (1730) de Agustín de San Juan Bautista. Hay otra de Cosme Membrado — de la generación de entresiglos- ${ }^{7}$ en el tomo II del Compendio histórico de la religión (1784), de José Pintón. El nombre "Juan Pío Membrado" figura en un volumen de El Pensador (1780) y con las iniciales “J. P. M.” en los Elementos de Derecho Patrio (1838), de Joaquín Escriche, pudiendo corresponder a Juan Pío Membrado Latorre o, también, a su nieto homónimo Juan Pío Membrado Ejerique, quien es el más que probable propietario de los Principios de solfeo (1857), de Pascual Pérez y Gascón: los incluyo en esta biblioteca porque debieron de ser adquiridos por su tío y preceptor musical, el cura Mariano. Este incorpora su firma a seis títulos, evidenciando de modo más claro la conciencia de crear una pequeña biblioteca propia: Explicación breve ... de la doctrina christiana, de Antonio Arbiol, con letra infantil y la

6 En la España rural del siglo XVIII se calcula que entre el 80 y el 90\% de la población no sabía firmar; el 10$20 \%$ alfabetizado correspondía a eclesiásticos, algún labrador rico y nobles y eventuales funcionarios como escribanos o maestros (Buigues, 2003: 424-425).

7 Orienta esta datación una licencia para cazar con dos galgos desde el 1 de agosto hasta finales de febrero de cada año, que obtuvo con fecha de 9 de julio de 1800 (Archivo Membrado, I, 10-O). 
advertencia "Si este libro se perdiere"; el diccionario español-francés de Francisco de la Torre y Ocón, El maestro de las dos lenguas (1728-1731); los dos tomos de una Biblia latina editada en 1759 por Du Hamel; la Universae Theologiae Moralis (1777) de Fulgenzio Cuniliati, en que a continuación del nombre del anterior dueño añade "Nunc autem ad Mariani de Membrado libris pertinet”; los Elementos de aritmética, álgebra y geometría (1801) de Justo Juan García, con la anotación "Alter inter libros Mariani a Membrado"; y en el tomo tercero de las Institutionum Elementarium Philosophiae (1824), de Andrés de Guevara y Basoazábal, donde figura una etiqueta encolada y manuscrita, a imitación de los exlibris impresos, y en dos del cuarto. Resulta más difícil identificar los juegos verbales garabateados en las guardas iniciales y finales de la antología de Cicerón de 1757, tal vez de los niños Membrado en sus clases de latín.

La mencionada Biblia había pertenecido a mosén Joaquín Soro Cortea, párroco de Belmonte, cuya hermana Ramona (1788-1855) casó con Juan Pío Membrado Latorre. Ese sacerdote anotó su nombre en cada uno de sus volúmenes y en otros seis libros: el Manuale Thomistarum de Jean-Baptiste Gonet (1680), la Explicación histórica, moral y mística de la sequencia del Santísimo Sacramento (1738) de fray Vicente María Oliver, el tomo primero de la obra de Melchor Cano (1774), la Pastoral de nuestro Santísimo Padre Benedicto XIV (1778), la Theologia scolasticodogmatica (1781) de Gotti y el famoso calepino Salas (1800). A excepción de este último, son libros teológicos para su formación en Zaragoza, según leemos en el de Gotti ("Ad usum Joaquimi a Soro Scolastici Theolgie [?] in Cibitate Cesaraugustana”), y para su posterior uso pastoral. En cuatro de ellos apuntó el precio pagado, cantidades no desdeñables como los 120 reales de vellón por el Gotti, una muestra no solo de la voluntad sino, sobre todo, de la posibilidad del acceso al libro del estamento clerical en ese contexto. ${ }^{8}$ Otro sacerdote pariente suyo, Francisco Soro, firma varias veces con distintas fórmulas: "In usum Fracisci Soro" a continuación del nombre de Joaquín en el ejemplar de Melchor Cano; antes de un "Membrado" indeterminado en las Institutiones Philosophicae (1770) de Jacquier (“Alter ex anumeratis inter libros Francisci Soro [rubricado]”); y en solitario en el Tyrocinium Morale Pro Scholasticis (1726) del fraile Madalena y en la gramática francesa de Galmace (1753) ("Ex libris Francisci Soro"). Estos ejemplos informan, además, de que algunos libros se regalaban o heredaban puntualmente. ${ }^{9}$

Buena parte de las compras librescas debieron de hacerlas en Zaragoza los jóvenes de la familia cuando estudiaban en las Facultades de Teología o Leyes y Cánones — según se denominaban entonces—-, necesitados de los títulos incluidos

8 A mediados del siglo XVIII los rectores del arzobispado de Zaragoza percibían 5.000 reales anuales de renta, mientras que los vicarios solo alcanzaban los 3.000 (Barrio Gozalo, 2010: 168); en la centuria siguiente, el maestro y organista de Belmonte cobraba 1.800 por ambos cargos (Madoz, 1846: 132), y los jornales de peones artesanos y oficiales oscilaban entre 5,5 y 14 reales en los años 1801-1850 (Martínez Martín, 1991: 64).

9 Francisco Soro era en 1791 el cura de la localidad zaragozana de Boquiñeni, suscriptor de una colección de textos sagrados de Benedicto XIV (1791: XIII). Joaquín Soro Cortea, tras cursar los siete cursos de Teología en Zaragoza (Archivo Histórico de la Universidad de Zaragoza, Libro de Matrículas, 1795, 1797, 1798, 1799, 1801, s. p.), tomó posesión del curato de Belmonte el 29 de mayo de 1805 (Archivo Membrado, A-I, 10-D, A-XIV, 1-B y I, 11-B) y, por delegación de Jorge Ariño, fue vicario de La Cañada de Verich; figura como "Cura de Foz Calanda”, su pueblo natal, en una lista posterior de suscriptores (Felipe de la Virgen del Carmen, 1828: [333]). 
en los respectivos planes de estudios. En otros momentos podían pedirlos por carta a los establecimientos de venta de la capital y recibirlos del mismo modo a través de la estafeta de Alcañiz, cuyo correo llegaba dos veces por semana a Belmonte (Madoz, 1846: 133). Unos cuantos eran libros usados, una práctica de la época que se advierte en las anotaciones de propietarios sucesivos: el título citado de Cuniliati, que de "Georgii Ariño et Ripot" — cura párroco de La Cañada de Verich - pasó a Mariano Membrado, sin duda a través de su tío Joaquín; la edición de 1525 de las Metamorfosis de Ovidio, que debió de pertenecer, por este orden, a Gabriel Piquero de la Vega y a Francisco Pérez Perea; el título de José de Sessé (1624), primero de un tal Alejandro Ferrer en 1696 y luego del abogado de Castelserás Manuel Ceperuelo; el prontuario de La Ripa, que fue del abogado Manuel Suñer, quien lo adquirió por 56 reales de vellón a un propietario anterior; el Remedio de deplorados, comprado por Antonio Nogueras a Paulino Gil; y el tratado de metafísica manuscrito de Torrente, propiedad sucesiva de Joseph Mateo y de Ramón Vallés. A excepción del primer caso citado, en los demás no añadieron su nombre los Membrado. Tampoco sucede en otras ocasiones en que figura un solo propietario, notándose la presencia de apellidos habituales en el Bajo Aragón, como Benito Ernicas en un repertorio de sermones de $1785 ;{ }^{10}$ dos Trullenque: Ramón, poseedor de las Orationes selectae (1816) de Cicerón, y José, de los Principios de cirujía (1826) de Legouas; y Matías Buisán en unos apuntes manuscritos de filosofía ( $\left.\mathrm{n}^{\circ} 79\right)$.

Merecen atención dos casos peculiares, que sugieren diversos circuitos de lectura. Uno es popular, con dos obras de Jerónimo Cortés, en que se hallan anotaciones de varios propietarios con caligrafía y ortografía deficientes: Francisco Navarro a la cabeza del de 1741, una fisionomía (“en velmonte en el ano 1817”); y Joaquín Vidal en la edición de 1760 de un lunario, donde la serie de nombres sugiere una propiedad compartida, además de otra transmisión en cadena hasta llegar a los estantes de los Membrado, por compra u otros medios, fruto de un interés práctico real o, tal vez, de la acción censora de los curas de la familia en su comunidad, sabedores de que algunas ediciones anteriores habían sido expurgadas por la Inquisición. ${ }^{11}$ Otro circuito es escolar, como revelan los tomos tercero y cuarto del manual de Guevara y Basoazábal, repetidos: Mariano Membrado poseyó un ejemplar de cada, Pedro Espallargas el cuarto y José Ruiz el tercero, que le costó 14 pesetas. Era este último de la cercana localidad de Torrevelilla -la Torre de Vilella- y casó con María Membrado Soro, única hermana de Mariano; ${ }^{12}$ y todos ellos debieron de recibir clases del cura Joaquín Soro, según se usaba en el espacio rural con los hijos de familias notables durante el Antiguo Régimen.

10 Un tal Benito Ernicas y Vicente consta como alumno de la Clase de Mayores y Retórica en las Escuelas Pías de Alcañiz, que realizó ejercicios literarios públicos en junio de 1818: puede tratarse de él o de algún antepasado suyo homónimo (Egercicios literarios..., 1818: 18).

11 Sufrieron expurgos puntuales dos ediciones del Lunario y Pronostico perpetuo (Barcelona, 1625; Valencia, Bordazar), en 1747, y otra de la Fisonomía (Valencia, 1695), además de prohibirse una edición de esta (Pamplona, Viuda de Martínez, s. d.) en 1750 (Índice de libros prohibidos, 1790: 66).

12 Su nombre aparece en un sobre con sello de Correos del Congreso de los Diputados, lacrado detrás: “Aragón. Sor. Dn. Jose Ruiz. Por Alcañiz. Torrevelilla” (Archivo Membrado, VI, 6); seguramente era una carta que le dirigía su amigo de juventud Ramón Membrado. 
Algunos datos mencionados permiten vislumbrar asimismo un circuito de profesionales, para quienes el libro constituía un instrumento esencial, como los mencionados abogados Ceperuelo y Manuel Suñer y el "practicante del Santo Hospital” Antonio Nogueras. Otros nombres ajenos sin más especificar actividad aparecen en el Corpus iuris civilis de Godefroy (Gregorio Lemendian [?]), en el título de agricultura de Arias y Acosta ("M. G. de Bayo") y en el de Medicina de Van Swieten (1761) ("D $\mathrm{D}^{\mathrm{n}}$ Michaelis Pardos", con fecha de 1765). Si añadimos Resolutionum moralium de Antonino Diana y el tomo III de los Ritos y ceremonias de los hebreos confutados ( $\left.\mathrm{n}^{\circ} 68\right)$, donde están tachadas las respectivas identificaciones de propiedad, tenemos un significativo repertorio de posesiones de segunda y tercera mano. Obtenidas por compras o también por donaciones, intercambios, apropiaciones o préstamos, no llegaron a rotularlas como suyas los Membrado.

Tres obras proceden de la biblioteca del convento de los Carmelitas Descalzos de Calanda o "de la Torre" —ahora conocido como "del Desierto"-, todas de temática religiosa: De officio curati (1620) de Possevino, cuatro volúmenes de los seis del Clypeus Theologiae Thomisticae de Gonet, y los seis de la Theologia Christiana dogmatico-moralis de Concina. Pudo haberlos llevado a Belmonte el fraile Pedro Ciprés, exclaustrado de ahí cuando la Desamortización de $1835 .{ }^{13}$ Los Membrado, que, según acostumbraban las familias hacendadas en la zona, eran protectores de la Orden, tenían reservado en su casa un "cuarto del fraile” para confesores, predicadores o limosneros de la misma cuando los visitaban; y alojaron luego al exclaustrado, quien se convirtió en el director espiritual de Juan Pío Membrado Latorre (Mur Gimeno, 1999: 131).

Otras anotaciones del cura Joaquín Soro, tan preocupado por el precio que había pagado por sus libros, remiten a préstamos librescos: "El Cura Zirujeda de Esta Librería tiene tres tomos de la Estrella del Alva, el Incógnito./ Mn. Miguel Cortés tiene Pláticas de Estevez, y los q. el dirá [?]/ Fr. Mathias Jayme Florez Clave Historica, y el $\mathrm{P}^{\mathrm{e}}$ Pinamonte", leemos antes del exlibris de su ejemplar de la Explicación de Oliver, un registro necesario para preservar su "librería". Aunque quizás esté indicando ahí desideratas de los títulos que poseían sus amigos, una pequeña comunidad de lectores, mayoritariamente eclesiásticos, que se intercambiaban lecturas y, probablemente, las comentaban.

13 La R. O. de 9 de marzo de 1836 ordenaba en su artículo 25 que los libros y archivos se entregasen a las bibliotecas provinciales, recién creadas, y aunque el artículo 24 permitía que los frailes pudiesen llevar "libros de su uso particular" cuesta creer que lo fuesen los de Concina y Gonet, en varios volúmenes infolio. Otra R. O. de 25 de enero de 1837 lamentaba las sustracciones para uso particular o venta de muchos de los libros desamortizados (ápud Bécares Botas, 1999: 20). 


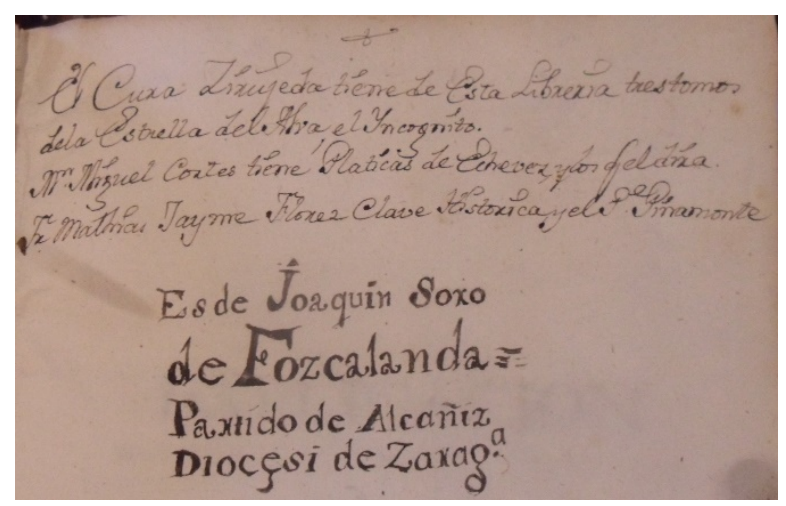

Figura 1. Exlibris de Joaquín Soro y registro de préstamos

Así pues, mediante distintos procedimientos, sucesivas generaciones de los Membrado fueron reuniendo libros que quedaron ubicados en la casa familiar hasta llegar a Mariano Membrado, depositario de todos ellos y de los propios, consistentes en las ediciones más modernas. Se había formado en primeras letras con su tío y padrino mosén Joaquín y como sacerdote en el Seminario Conciliar de Vich, y desde 1833 hasta su muerte en 1865 fue párroco de Belmonte, un cargo que prefirió a una canonjía en Lérida (Mur Gimeno, 1999: 131-133), ${ }^{14}$ porque desde allí, en la casa que hizo construir contigua a la familiar, podía ejercer no solo el poder local sino más allá, muñidor electoral en la elección de su hermano Ramón como diputado por Teruel durante la Década moderada y orientador de su acción política. ${ }^{15}$ La conciencia que él y sus predecesores tuvieron de crear una biblioteca conjunta parece relativa, apreciable en el hecho de que conservaran reunidos los libros de sus antepasados, entre los cuales los propios marcados con sus respectivos y esporádicos exlibris, sin que exista constancia de un espacio específico reservado a ese efecto. Actualmente, está ubicada en el antiguo despacho de don Juan Pío, que custodió allí los libros de sus antepasados junto a documentos legales o administrativos — atados en paquetes-, que forman el actual Archivo Membrado, muy extenso, creado por Ramón Mur. Como se ha dicho, no existe en él ningún inventario ni de las bibliotecas personales parciales ni de la familiar resultante ni se mencionan en las disposiciones testamentarias. ${ }^{16} \mathrm{El}$ resultado es una suma sobrevenida con el paso del tiempo al hilo de las necesidades de los distintos poseedores lectores, que no vieron en el libro un patrimonio tasable sino un instrumento de uso coyuntural o cotidiano.

14 El Arxiu i Biblioteca Episcopal de Vic no conserva actualmente libros de matrícula de sus antiguos seminaristas, según me informa el archivero Rafel Ginebra, como tampoco la Biblioteca del Seminari Diocesà.

15 Se puede rastrear ese factor en la correspondencia que intercambiaron: 13 cartas escritas entre 1844-1845 y una de 1860 (Archivo Membrado, VI, 6); y otras tres de 1845 sobre el proyecto de Ramón de marchar a Filipinas (Archivo Membrado, VI, 5).

16 La lista los “bienes muebles” de don Mariano “consistían en ropa de su uso personal, cubiertos de plata, sillas, mesas, camas, dos reloges, trigo, cebada, patatas, aceite, ganado lanar y demás enseres que se necesitan para el servicio de una casa, todo lo cual se tasó y justipreció” ("Escritura de inventario y adjudicación de los bienes del difunto D. Mariano Membrado Soro”, 28 septiembre 1882, Archivo Membrado, 28). 


\section{Características del fondo}

El proceso de configuración descrito y su tamaño alejan a esta biblioteca de las de nobles, eruditos y políticos en el siglo XVIII, tan notables (Sánchez Mariana, 1993: 64-76), más cercana a las reunidas por los grupos profesionales en la España isabelina también por su finalidad práctica. Se acerca al tamaño medio de estas con 106 títulos que suman 172 volúmenes: de tres de los 99 impresos hay varias ediciones $\left(\mathrm{n}^{\circ} 7,21,50\right)$ y algunas obras constan de más de un tomo - aunque no todas estén completas-, más 7 manuscritos. ${ }^{17}$ Aparte de desapariciones puntuales, bien pudieron realizarse compras selectivas de los tomos que se necesitaban o que era posible adquirir en el momento. Por otro lado, se observa el afán por conseguir algunas adiciones o continuaciones: el tratado jurídico de Luis de Molina $\left(\mathrm{n}^{\circ} 70\right.$ y 71) o el Febrero reformado ( $\left.n^{0} 35\right)$ completado por la Práctica criminal de José Marcos Gutiérrez (nº 51).

La clasificación por materias resulta un elemento central en la caracterización de una biblioteca, que, como se ha dicho, se relacionará aquí con los autores presentes y aspectos tangenciales como fechas y lugares de edición, lenguas y algunas características materiales con el fin de reconstruir el universo mental de los señores rurales la etapa final del Antiguo Régimen. Aunque la taxonomía de la Biblioteca Membrado no sea fácil, ya que algunas materias se entrecruzan y otras no están demasiado definidas, predomina con claridad el tema religioso, con 42 títulos, seguido de lejos por los 15 de derecho y los 14 de la heterogénea categoría de la literatura. Los restantes grupos tienen una importancia menor, según se detalla a continuación, destacando los dedicados a los idiomas y a las ciencias: ${ }^{18}$

Tabla 2. Clasificación temática de la Biblioteca Membrado

\begin{tabular}{|l|r|r|r|r|}
\hline Materia & Impresos & Mss. & Total & \% \\
\hline Teología y religión & 42 & & & 44,3 \\
\hline Derecho & 15 & & & 14,1 \\
\hline Literatura & 12 & 2 & 14 & 13,2 \\
\hline Ciencias puras y aplicadas & 8 & & & 7,5 \\
\hline Filología & 7 & & & 6,6 \\
\hline Medicina & 5 & & & 4,7 \\
\hline Historia & 4 & & & 3,7 \\
\hline Filosofía & 3 & 5 & 8 & 2,8 \\
\hline Música & 2 & & & 1,8 \\
\hline Obra varia & 2 & & & 1,8 \\
\hline & 99 & 7 & 106 & \\
\hline
\end{tabular}

17 Las bibliotecas de más de 200 títulos eran las predominantes entre médicos y abogados en el Madrid del siglo XIX, aunque el tamaño medio era de 154 títulos en cifras de Martínez Martín (1991: 95), quien entre los distintos grupos analizados no incluye el de los eclesiásticos.

18 Reformulo las denominaciones de la CDU, aunque separo la Música (que ahí se incluye entre Bellas Artes y literatura) y añado una “Obra varia” para las de difícil clasificación. 
La presencia de varios sacerdotes en la familia hace lógico ese predominio, con dos miembros directos: Joseph Membrado Bayod, el primero en cursar estudios superiores en Zaragoza, y Mariano Membrado Soro; y los parientes políticos mosén Jacinto Latorre, hermano de Francisca Latorre y párroco local, y los mencionados Francisco y Joaquín Soro. Esta circunstancia va paralela a la importancia eclesiástica en todos los aspectos de la vida, entre los cuales el mundo editorial: el clero ocupaba un lugar relevante en la República de las Letras en el siglo XVIII, en especial el vinculado a órdenes religiosas, y evidentemente producía obras para consumo interno o de los fieles, propias o reediciones de otras anteriores, en una cantidad reflejada en fiel proporción en la Biblioteca Membrado. ${ }^{19}$ Describe en ella un camino progresivo que comienza en la formación infantil y juvenil, continúa con la específica sacerdotal y acaba en el ejercicio pastoral combinado con lecturas personales. Orientado a instruir a los niños Membrado estaba el Compendio histórico de la religión, de José Pintón ( $\mathrm{n}^{\circ} 80$ ), libro muy editado en el XVIII y XIX que usaron instituciones como los Reales Seminarios de Nobles (Gimeno Puyol, 2017); el catecismo en castellano de Planas y el latino de Guillermo Ramón (nº 81 y 87); y un título del franciscano Antonio Arbiol, exitoso divulgador de la mística entre el clero regular (Egido, 2003: 418), cuya Explicación breve doctrinal $\left(\mathrm{n}^{\circ}\right.$ 6) fue leída por el pequeño Mariano Membrado. Destaca luego el grupo de textos latinos sobre teología moral, de corte tomista principalmente, que debieron de ser lecturas obligadas en la Facultad de Teología de Zaragoza y en el Seminario de Vich: obras fundamentales del mismo Santo Tomás de Aquino (n $\left.{ }^{\circ} 100\right)$ y de insignes autores de su orden, algunos de siglos anteriores: Tomás Madalena ( $\mathrm{n}^{\circ}$ 63), Melchor Cano ( $\left.\mathrm{n}^{\circ} 13\right)$, Cuniliati $\left(\mathrm{n}^{\circ} 22\right)$, Gonet $\left(n^{\circ} 46,47\right)$, Concina $\left(n^{\circ} 19\right)$, Gotti $\left(n^{\circ} 48\right)$, Patuzzi $\left(n^{\circ} 76\right)$ y Wigandt $\left(n^{\circ} 105\right)$. Otras órdenes están representadas: el franciscano Villalobos ( $\left.\mathrm{n}^{\circ} 104\right)$; el reputado Antonino Diana ( $n^{\circ}$ 26), de los Teatinos; el jesuita italiano Nicolai Mazzota $\left(n^{\circ} 67\right){ }^{20} \mathrm{Y}$ también clérigos seculares como Jacques Marchant, profesor de Teología (n ${ }^{\circ}$ 64), y Peter Ludwig Danes ( $\mathrm{n}^{\circ}$ 24), doctor en Lovaina y su rector en 1735.

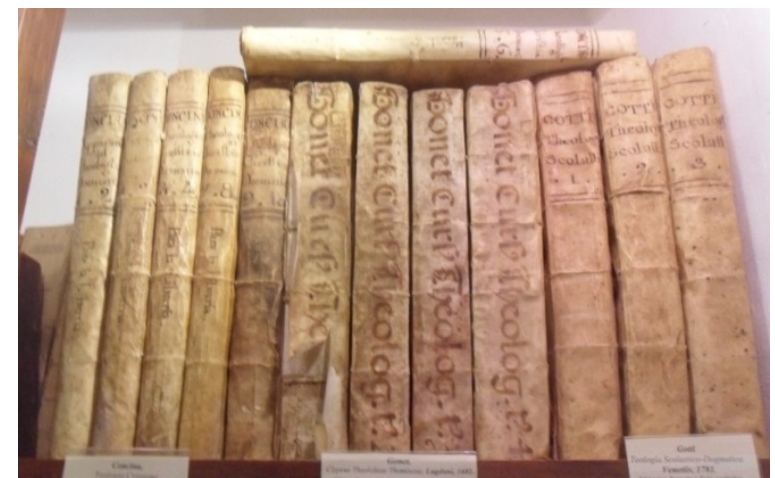

Figura 2. Detalle de títulos religiosos en la Biblioteca Membrado

19 El clero representaba el 67,5\% de la producción impresa en la primera mitad del siglo XVIII y el 45\% en la segunda, pero seguía siendo el principal estamento en la reedición de obras en latín (Buigues, 2003: 293-295).

20 Los dominicos, que eran el 9,8\% del clero regular, ascendían al 11,06\% entre sus autores, una proporción que excedían los jesuitas, que con una población del 7,3\% constituían el 16,94\% de autores (Buigues, 2003: 295). 
Entre los libros religiosos un buen grupo parece orientado a la lectura personal o al ejercicio pastoral. Sobresalen distintos repertorios de predicación $\left(n^{0} 15,27,40\right.$, 87), que proliferaron en el XVIII, y explicaciones litúrgicas o doctrinales $\left(\mathrm{n}^{\circ} 32\right.$, $74,83)$, además dos obras del cultivado Benedicto XIV $\left(\mathrm{n}^{\circ} 9,10\right)$, que tanto se preocupó por la formación de los sacerdotes. Las dos ediciones de la Vulgata latina -la del teólogo dominico Hugo de San Caro, uno de los primeros correctores bíblicos, muy editada desde 1642 (1754), y la anotada por el filósofo francés JeanBaptiste du Hamel (1759) — estaban destinadas a estos, capaces de leerla, mientras que la traducción de 1790-1793 del escolapio Felipe Scío, auspiciada por Carlos IV, se abría a más lectores, algo después de que en 1782 se autorizase en España la Biblia en lengua vulgar, aunque su tamaño y extensión en diez volúmenes la hiciesen poco manejable y asequible. ${ }^{21}$ Era patrimonio de buenas bibliotecas, igual que las colecciones de historia sagrada y eclesiástica en formato mayor que esta conserva incompletas: 15 tomos de los 20 que componían la del abad BeraultBercastel ( $\mathrm{n}^{\circ}$ 11), 12 de los 30 de la Biografía eclesiástica $\left(\mathrm{n}^{\circ} 12\right)$ y tres del santoral latino de Tamayo y Salazar ( ${ }^{\circ}$ 99); así como otras ediciones menos voluminosas como el Teatro histórico de las iglesias del Reyno de Aragon del capuchino fray Lamberto de Zaragoza $\left(\mathrm{n}^{\circ} 59\right)$ y varios tomos sueltos de un compendio hagiográfico en español $\left(\mathrm{n}^{\circ}\right.$ 85), género edificante y adecuado para la "lectura familiar y comunitaria" (Egido, 2003: 416). De la abundante oferta existente de libritos de devoción en la época solo ha quedado una novena a la Virgen del Milagro ( $\left.{ }^{\circ} 25\right)$, además de las composiciones del licenciado Homedes a diferentes advocaciones comarcales ( $\mathrm{n}^{\circ}$ 52), tal vez porque su espacio no era la biblioteca sino el oratorio, reservado a las mujeres, menos letradas. ${ }^{22}$ Las lecturas personales más elevadas las tuvieron que efectuar los varones, en especial los sacerdotes; entre ellas encontramos algunas de orientación ilustrada: un tomo de El hombre feliz, novela ascético-filosófica muy reeditada del portugués Teodoro de Almeida ( $\mathrm{n}^{\circ}$ 5), fraile ilustrado; y El protestantismo comparado con el catolicismo en sus relaciones con la civilización europea $\left(\mathrm{n}^{\circ}\right.$ 8), obra magna de Jaume Balmes, compañero de estudios del cura Mariano en Vich. Otras lecturas, sin embargo, presentan un tinte ultramontano con famosas defensas del catolicismo frente a otras religiones: el Verdadero carácter de Mahoma y de su religión (1793) del carmelita zaragozano Manuel de Santo Tomás, conocido por sus posiciones serviles; los Ritos y ceremonias de los hebreos confutados (1800), una obra de 1736 tan polémica como reeditada del converso italiano Paolo Sebastiano Medici; y la primera edición española de Del protestantismo y de todas las herejías (1853), del francés Auguste Nicolas, controvertido apologeta católico.

Según queda dicho, el derecho configura el segundo bloque temático en importancia de esta biblioteca, para uso de los abogados de la familia. Matías

21 Teófanes Egido ofrece interesantes datos sobre las lecturas devocionales: sermones, Biblia... (2003: 417, 421). Sobre la Biblia de Scío, también François Lopez (2003: 359).

22 Junto a un devocionario consignado por Mur Gimeno que no he localizado (ver nota 2), son restos de una presencia “desproporcionada, cuantitativa y cualitativamente" de libros y libritos de devoción sobre otras materias en el siglo XVIII (Egido, 2003: 415). María Francisca Latorre, de Peñarroya de Tastavins, que casó en 1775 con el Dr. Matías, sabía leer y escribir con algunas limitaciones (Mur Gimeno, 1999: 43-44). 
Membrado Bosque, el primero de ellos, ingresó en 1757 en la Facultad de Leyes de Zaragoza, ciudad donde se doctoró en febrero de 1764, abrió un bufete jurídico y fue Decano del Colegio de Abogados, por lo que pasaba temporadas allí, lejos de la rutina del pequeño lugar (Mur Gimeno, 1999: 30-35, 44); ${ }^{23}$ su nieto Ramón Membrado Soro, que entró en la misma Facultad en 1833, fue entre 1843-1845 pasante en el bufete de Francisco Ram de Viu en Teruel (Mur Gimeno, 1999: 121), diputado de esta circunscripción durante tres legislaturas y gobernador civil de la provincia en $1850 .{ }^{24}$ Hay que subrayar la presencia de ediciones antiguas, de los siglos XVI y XVII, en este ámbito: los escritos por el juriconsulto Luis de Molina $\left(n^{\circ} 71,72\right)$, el tratado de José de Sessé $\left(n^{\circ} 94\right)$ y otros sobre Derecho foral aragonés ( $\mathrm{n}^{\circ}$ 41, 82), además del título de Juan Francisco La Ripa, uno de los últimos foralistas aragoneses ya en el XVIII ( $\mathrm{n}^{\circ}$ 60), pues debían de integrar los programas universitarios en Zaragoza, como también los que abordaban aspectos históricos en España — sobre la Chancillería de Valladolid $\left(\mathrm{n}^{\circ} 37\right)$ — o el Derecho Civil de Godefroy ( $\left.n^{\circ} 44\right)$, muy difundido en toda Europa. Algunas de estas ediciones se compraron usadas, como queda dicho. La finalidad profesional se advierte en los Elementos de Derecho Patrio del jurista turolense Joaquín Escriche $\left(\mathrm{n}^{\circ} 34\right)$, guía para jóvenes abogados, y en manuales para la práctica notarial, administrativa o forense: los de José Febrero ( $\mathrm{n}^{\circ}$ 35) y de José Juan y Colom ( ${ }^{\circ}$ 57), tan editados en los siglos XVIII y XIX, y uno de los volúmenes de la primera edición del penalista José Marcos Gutiérrez, antes citada ( $\mathrm{n}^{\circ}$ 51). Títulos relacionados con las medidas desamortizadoras ( $\left.n^{\circ} 58\right)$ y con el gobierno local $\left(n^{\circ} 91\right)$ debieron interesar a los Membrado para atender sus propiedades o el gobierno municipal. Con los condicionantes aludidos, el conjunto resulta tradicional y práctico, sin presencia de títulos de las nuevas corrientes jurídicas europeas difundidos en España como Cesare Beccaria, reformador del derecho penal, traducido en 1774; y, sobre todo, de los traducidos en el XIX: Montesquieu, Heinecio y otros formuladores del derecho natural y de gentes como Bentham, Burlamaqui y Vattel (Martínez Martín, 1991: 101-102). También falta la Novísima Recopilación (1805). ${ }^{25}$ Dado que Ramón Membrado Soro ejerció fuera de Belmonte, cabe pensar que su hipotética biblioteca personal no está integrada en esta familiar.

La historia académica, relacionada la materia anterior, ocupa menor espacio: los Anales de Zurita ( $\left.{ }^{\circ} 106\right)$ - cuyos 7 tomos poseyeron- y un Discurso $\left(\mathrm{n}^{\circ} 28\right)$ sin identificar sobre la ciudad de Zaragoza. Otros títulos de carácter histórico están orientados a la formación inicial: el compendio de historia de España del jesuita

23 Figura como estudiante de tercer año entre los "Matriculados en Leyes y Cánones año de 1759" (Archivo de la Universidad de Zaragoza, Libro de Matrículas 1759, f. 93). Por encargo del Colegio de Abogados, organizó la fiesta de su patrón San Ivo en 1792, encomendando la oración panegírica a Joaquín Mazod, amigo suyo y rector de la parroquia de Santa Cruz de la ciudad (Mur Gimeno, 1999: 35).

24 Aparece registrado en los libros de matrículas conservados, de los cursos 1833-1834, 1834-1835 y $1835-1836$ (Archivo de la Universidad de Zaragoza). Fue diputado en las legislaturas 1844-1845 (elecciones 3-9-1844), 1845-46, 1857-58 (elecciones 25-3-1857) (Congreso de los Diputados, 2017: ACD, Serie Documentación Electoral: $\left.24 n^{\circ} 64 ; 41 n^{\circ} 42\right)$.

25 Existen varios volúmenes editados en 1807 (I, III, IV y VI), con una etiqueta impresa en caracteres decimonónicos de un propietario anterior, lo que apunta a una adquisición de Juan Pío Membrado. 
Duchesne ( $\left.\mathrm{n}^{\circ} 31\right)$, en una traducción diferente a la exitosa del padre Isla (García Cuadrado, 2000), y el manual de historia antigua y mitología de Escosura ( $\left.\mathrm{n}^{\circ} 33\right)$.

$\mathrm{Y}$ es que buena parte de los libros, según se ha ido comentando, parecen destinados a instruir en primeras letras a los vástagos de la familia. Sus preceptores fueron, bien seguramente, los tíos sacerdotes, párrocos del pueblo; el espacio lectivo, la Casa Membrado o alguna dependencia parroquial; ${ }^{26}$ y la instrucción, multidisciplinar, en torno a la religión y la historia comentadas y, sobre todo, las lenguas. Conforme a los usos vigentes, el mayor peso lo tiene el latín con un repertorio que refleja el canon habitual en las escuelas de latinidad y gramática en la época (Viñao, 2003: 403-404): el llamado “Calepino Salas” hispano-latino (n ${ }^{\circ}$ 86) - muy editado entre 1724 y 1832 —, la gramática latina de Nebrija (nº 72) editada hasta mediados del siglo XIX - y una serie de textos clásicos, desde las Metamorfosis de Ovidio ( $\left.\mathrm{n}^{\circ} 75\right)$ a varias recopilaciones en elocuente evolución: la selección del escolapio Agustín de San Juan Bautista $\left(n^{\circ} 3\right)$ —que es la más antigua, del primer sacerdote Membrado-, dos de Cicerón de centurias diferentes $\left(\mathrm{n}^{\circ} 16,17\right)$ y una antología de las Escuelas Pías $\left(\mathrm{n}^{\circ} 1\right)$ con paratextos ya en castellano, cuyo tomo I (1845) corresponde a la última generación. Anotaciones y subrayados en algunos ejemplares evidencian su utilización escolar. Está presente asimismo el francés, lengua de cultura europea cuyo estudio cobró auge en la España ilustrada: la gramática de Galmace $\left(\mathrm{n}^{\circ} 42\right)$, tan editada, y un diccionario español-francés ( $\left.n^{\circ} 102\right)$. En cambio, se echan de menos diccionarios y gramáticas castellanas, una parcela representada por manuales de escritura práctica: uno con muestras y otro epistolar $\left(\mathrm{n}^{\circ} 23,101\right)$, este último apto también para la edad adulta.

De tema filosófico son, precisamente, dos obras de carácter formativo que tratan de conciliar Ilustración y religión: las Institutiones Philosophicae de François Jacquier, famoso matemático y profesor universitario, de la Orden de los Mínimos, muy editadas desde 1757 hasta el primer tercio del siglo XIX; e Institutionum Elementarium Philosophiae ad usum Studiosae iuventutis del jesuita novohispano Andrés de Guevara y Basoazábal. Cinco cuadernos manuscritos recogen lecciones de filosofía desde una óptica cristiana destinadas al estudio universitario, y sugieren la existencia de un notable mercado de copia y venta de apuntes, todos con letra cuidada, títulos ornamentados e ilustraciones y encuadernados en pergamino: uno es obra del profesor de la Universidad de Zaragoza Mariano Torrente $\left(n^{\circ} 103\right)$ - con exlibris de dos propietarios anteriores - y otro procede de la de Valencia $\left(\mathrm{n}^{\circ} 38\right)$ - como probablemente los $\mathrm{n}^{\circ} 79$ y 85-, donde ningún Membrado cursó estudios— $-{ }^{27}$ Es un conjunto filosófico bastante más monocromo

26 Según Mur Gimeno (1999: 30), el Dr. Matías recibió de niño formación clásica en el convento de los Carmelitas Descalzos de Calanda con fray José de Santa Teresa, aunque no he localizado evidencias de enseñanza organizada ahí (Vidiella, 1909); más lógico parece que fuese tutelado por su tío paterno mosén José Membrado Bayod. Sucesivamente, en las siguientes generaciones, mosén Jacinto Latorre instruiría a Juan Pío, hijo de su hermana Francisca; mosén Joaquín Soro a los hijos de su hermana Ramona: Joaquín, Mariano ahijado suyo (Mur Gimeno, 1999: 92)—y Ramón; y, finalmente, mosén Mariano a Juan Pío Membrado Ejerique.

27 Mariano Torrente figura entre los profesores que participaron en el claustro excepcional del 15 de octubre de 1808, en que los profesores presentes hubieron de adoptar medidas ante la invasión de España por las tropas francesas, AHUZ, Libros de Gestis, curso 1807-1808, t. XXXIX, f. 111 y 218 (ápud Vicente, 2016: 170). 
y clerical que el de otras bibliotecas de la época, estudiadas por Martínez Martín (1991: 104).

El abanico multidisciplinar lo completan varios manuales de introducción a las matemáticas - entre ellos el de Alberto Lista- $\left(\mathrm{n}^{\circ} 43,62\right)$ y a la historia natural $\left(n^{\circ} 30,98\right)$, junto a las enseñanzas musicales $\left(n^{\circ} 65,77\right)$, pieza esencial en los estudios eclesiásticos.

Fuera del ámbito formativo estricto, diversas obras parecen encaminadas a su uso práctico e inmediato en distintos campos. En el de las ciencias aplicadas se incluyen dos tratados de agricultura $\left(\mathrm{n}^{\circ} 7,66\right)$, ambos editados en el siglo XIX, que debieron aplicarse a mejorar las explotaciones agrícolas de los Membrado. Pero también obras de otro signo, divulgativas entre los estratos populares, como las dos mencionadas de Jerónimo Cortés, astrólogo, matemático y naturalista valenciano de finales del siglo XVI, muy editado en el XVIII: un lunario y una fisionomía dos ejemplares de esta—, que contenían informaciones para el cultivo de la tierra o los remedios naturales, respectivamente, tan útiles en el mundo rural.

Las obras médicas, en grupo aparte, sorprenden por su número $\left(\mathrm{n}^{\circ} 39,61,95\right.$, 99, 97) en la biblioteca de una familia que no tuvo médicos. De tres de ellas sabemos que tuvieron propietarios anteriores, entre los cuales el citado Antonio Nogueras "practicante en el Santo Hospital", es decir, alguien que ejerció la medicina bajo la supervisión de un médico, según la acepción de la época, y que además recopiló un recetario a base de plantas medicinales autóctonas. ${ }^{28}$ En el aislado paraje de Belmonte, sin infraestructuras sanitarias al alcance, la salud tuvo que ser una preocupación, y más con epidemias cíclicas como el cólera, que en 1855 acabó con varios Membrado. Es difícil conjeturar si proceden de la enfermería del Convento calandino de la Torre — sin su exlibris - o de compras intencionadas para uso propio.

Aplicada a las obras destinadas al entretenimiento en un sentido amplio, la literatura ocupa el tercer lugar numérico en esta biblioteca. Se excluyen ahí los clásicos latinos antes aludidos $\left(\mathrm{n}^{0} 1,3,16,17,75\right)$ por su orientación más formativa que recreativa, si bien se nota la falta de traducciones muy difundidas entre la juventud de la época como las Aventuras de Telémaco de Fénelon (García Bascuñana, 2015), El nuevo Robinson del alemán Campe o las autoras francesas Leprince de Beaumont y De Genlis (Bolufer Peruga, 2002). Sí está presente el Quijote, clásico que en el siglo XVIII revivió entre un amplio público en ediciones lujosas o populares: un ejemplar en $8^{\circ}$ aquí conservado de la primera parte evidencia en su deterioro su carácter de lectura "de faldriquera" (Martínez Martín, 1991: 473). Otras dos obras de éxito ofrecen lecturas mixtas, con el plus de lo edificante o informativo: la citada novela religiosa de Almeida y la relación autobiográfica de los viajes de Jorge Juan. En este sentido, la Biblioteca Membrado, al igual que otras bibliotecas privadas durante la Edad Moderna, recoge una pequeña proporción de lo que, según ha estudiado François Lopez, posee "carácter literario" desde nuestros ojos contemporáneos, que apenas supuso en ellas un 4\% (2003: 471); aunque ya no se incorpora a la boga de novelas en

28 Archivo Membrado, VIII, 4, manuscrito con distintas caligrafías. 
colecciones o entregas, popularizadas hacia los años 40 y 50 del siglo XIX junto a otros géneros, que en las de los profesionales madrileños supusieron entre un 9,57 y un 14,56\% de sus fondos (Martínez Martín, 1991: 161, 355-362). La literatura de creación aparece en dos cuadernos manuscritos, muy significativos porque apuntan a una especificidad del mundo rural, informando de un pequeño círculo de eruditos locales y de la demanda correspondiente: el del licenciado Homedes, autor de composiciones destinadas a su representación en las festividades religiosas de la comarca, vinculado a una familia de funcionarios allí; ${ }^{29}$ y la recopilación de Antonio Huerta, de autoría no indicada, en un espectro más variado de géneros y temas, para lectura individual o tertulias más reducidas. No encontramos, en cambio, tratados ascéticos religiosos, que según Egido (2003: 418) dominaron la vida virtuosa en la Ilustración española, pero sí un repertorio orientado a la reflexión personal o el uso social, a cargo de autores laicos en su mayoría: por un lado, la polifonía de géneros ascéticos, políticos, morales y alegóricos de la obra completa de Baltasar Gracián editada en el siglo XVII (1664), una recopilación de tratadistas barrocos en una edición de $1711\left(\mathrm{n}^{\circ}\right.$ 2) y el posbarroco Deleyte de la discreción del duque de Frías (1749); por otro, los modernos ensayos a la manera feijooniana de Los fantasmas de Madrid (1761-1763) del benedictino Gómez Barreda y un volumen de los discursos de El Pensador Matritense (1759).

Otros dos títulos de difícil adscripción temática inciden en la dimensión mundana en diferentes sentidos: el manual de urbanidad El hombre fino $\left(\mathrm{n}^{\circ}{ }^{86}\right.$ ), por cuyas fechas debió de pertenecer al cura Mariano o a sus hermanos; y un volumen bastante anterior del Mercurio histórico y político de agosto de $1759 .{ }^{30}$

Cabría considerar, por último, los libros que pudieron haber estado en la Biblioteca Membrado pero que no se han conservado por distintas razones. Las dos muestras de El Pensador y el Mercurio dan fe de que las publicaciones periodísticas, vendidas por suscripción, traspasaron en el siglo XVIII el ámbito madrileño y llegaron a lugares tan remotos como un pequeño pueblo bajoaragonés, aunque se trata de dos tipologías diferentes: el primero constituía una colección de ensayos con valor atemporal, aptos para su relectura más allá de su momento de edición, mientras que el segundo era un noticiario de actualidad, por lo que resulta excepcional que haya pervivido en los estantes de la biblioteca. ${ }^{31}$ No ha quedado rastro del Diario de las Sesiones del Congreso de los Diputados o de la Gaceta de Madrid —que ejercía como boletín oficial—, con que el cura Membrado debía de informarse del curso parlamentario para poder guiar a distancia las intervenciones políticas de su hermano Ramón. ${ }^{32}$ Falta también el famoso Diccionario geográfico

29 Se conserva un libro de 1579 del escribano de Belmonte Joan Omedes, con distintos documentos del siglo XVII (Archivo Membrado, I, 11).

30 El periódico, que se editó mensualmente entre 1738 y 1784 y estuvo administrado por el Estado desde 1756, publicaba noticias europeas traducidas del Mercure historique et politique de La Haya, además de noticias españolas.

31 Para datos sobre la distribución geográfica de los periódicos, el perfil y motivaciones de sus lectores, véase Larriba (2003: 465-468).

32 El cura Membrado en la primera carta a su hermano comentaba el “discurso de apertura” de la legislatura pronunciado por Isabel II el 10 de octubre de 1844 y sus alusiones al clero (28-11-1844, Archivo Membrado, 
de Pascual Madoz, a quien precisamente este último entregó en Madrid informaciones sobre Belmonte redactadas por el escribano público Francisco Estevan y Bosque con la probable colaboración de Mariano Membrado, por cuyos afanes la entrada resultó muy extensa (Mur Gimeno, 1999: 13).

La relativa variedad temática reseñada no traspasa al terreno idiomático. Es esta una biblioteca muy poco variada: ni lecturas en francés, que inducen a pensar que su estudio fue elemental o esporádico; ni en catalán, que era el idioma autóctono y familiar pero no el de cultura, pues Belmonte pertenecía a la diócesis de Zaragoza y al partido judicial de Alcañiz, dentro de Aragón, y a ambas ciudades vincularon preferentemente sus estudios y actividad profesional los Membrado. Así solo encontramos libros en castellano y en latín, este en una proporción notable en los títulos de teología y derecho, ya que en esa lengua se impartían ambas materias en los estudios superiores de la época y todavía mantenía una presencia notable en la industria editorial en el siglo XVIII. ${ }^{33}$

\begin{tabular}{|c|c|c|c|c|c|c|c|}
\hline Lenguas & $\begin{array}{l}\text { Títulos } \\
\text { s. XVI }\end{array}$ & S. XVII & S. XVIII & S. XIX & Sin datar & Total & $\%$ \\
\hline Castellano & - & 5 & $34+2$ mss. & 26 & 1 & 68 & 64,1 \\
\hline Latín & 3 & 10 & $16+5$ mss. & 4 & - & 38 & 35,8 \\
\hline & 3 & 15 & $50+7$ mss. & 30 & 1 & 106 & \\
\hline
\end{tabular}

Tabla 3. Clasificación lingüística de la Biblioteca Membrado

La mayoría de los autores son españoles, siguiendo en importancia los franceses (15) —algunos ocultos por los nombres de sus respectivos traductores - e italianos (10). ${ }^{34}$ Solo dos clásicos latinos, además de los incluidos en una antología (n $\left.{ }^{\circ} 1\right)$, dos holandeses - el dominico Martin Wigandt (†1708) y el médico Gerard van Swieten (1700-1772)—, el flamenco Peter Ludwig Danes (1684-1736) —o PierreLouis Danès- y el portugués Almeida. La variedad en el origen autorial es mayor en los títulos más antiguos, que versan sobre teología o derecho, y entre ellos destacan frailes predicadores. Como resultado, la Biblioteca Membrado exhibe un cosmopolitismo católico conservador, primero en latín y luego traducido, que excluye las obras de los philosophes y suple best sellers de la Ilustración española como Feijoo con las reflexiones de su seguidor Gómez Barreda y los pensamientos de Clavijo y Fajardo. No aparecen las novelas tan en boga a mediados del XIX. Y tampoco, por supuesto, libros prohibidos.

VI, 6); fue recogido por el Diario de la cámara, que también se editó por legislaturas desde 1838 y como colección en el último tercio de siglo (Diario de las Sesiones de Córtes, 1876: sesión 1-10-1844, n 1: 2-3).

33 Según estudia Buigues, a medida que avanzaba el siglo XVIII, las impresiones en castellano fueron multiplicando las latinas, del doble de títulos en 1700-1724 a quintuplicarla en el último tercio; las impresiones en catalán fueron progresando de las 324 iniciales hasta caer a una cifra similar con la Revolución francesa (2003: 310-311).

34 Entre los autores antiguos franceses se hallan Hugo de San Caro — Hugues de Saint Cher (1190?-1263)—y el jurista Denis Godefroy (1549-1622). Entre los italianos hay autores medievales o renacentistas como Tomás de Aquino (1224-1274), Giovanni Battista Possevino (1533-1552) y Antonino Diana (1586-1663), además del papa Benedicto XIV (1675-1758). 
Asimismo, los lugares de edición remiten a un universo impresor europeo inicial en el que, en progresión descendente, van desapareciendo libros extranjeros. Zaragoza predomina en los títulos del siglo XVII, seguida de Lyon, ciudades de edición de dos de los conservados del XVI, además de Estrasburgo -Argentorati-, donde se imprimieron las Metamorfosis de Ovidio, en una edición muy rara a cargo de Johann Knobloch, editor de textos protestantes en la época de la Reforma hasta su muerte en 1528 (Gilmont: ed. digital). Destaca Madrid, con notable ventaja en los siglos XVIII y XIX, seguida de Barcelona y Valencia, acorde en proporción a la producción impresa a lo largo de ese tiempo. ${ }^{35}$ Merece mencionarse Venecia, de donde proceden textos religiosos en latín, con tres obras editadas por la Typographia Balleoniana, que estuvo activa entre 1719 y 1844, entre ellos la Vulgata de Du Hamel ( $\mathrm{n}^{\circ}$ 29), en una edición que no he localizado. ${ }^{36}$ Tampoco aparecen en los principales catálogos otras dos editadas en sendas imprentas aragonesas que operaron durante el XVIII y que, seguramente, tendrían tiradas reducidas: la de Arbiol en Calatayud $\left(\mathrm{n}^{\circ} 6\right)$ por Juan de Aguirre y el M. Tullii Ciceronis Orationes selectae en Zaragoza ( $\left.\mathrm{n}^{\circ} 16\right)$ por Francisco Moreno; y lo mismo la del segundo tomo del repertorio de Chevassu $\left(\mathrm{n}^{\circ}\right.$ 15). En esta progresión cronológica, se observa una evolución hacia un tamaño manejable para un uso cotidiano, en que los infolios van perdiendo peso: lo son los dos títulos más antiguos $\left(\mathrm{n}^{\circ} 70,82\right)$ y nueve de los 14 de la centuria siguiente $\left(\mathrm{n}^{\circ} 26,41,47,64,71\right.$, 94, 99, 100, 106), entre los cuales sobresalen los Anales de la Corona de Aragón de Zurita. De las ediciones del XVIII, cabe señalar algunas editadas con cierto lujo y formato grande: las tres de la Biblia — la de Du Hamel costó a Joaquín Soro 72 reales de vellón-, en folio menor, a dos colores y con grabados; los tres tomos infolio de la Theologia scolastico-dogmatica de Gotti — que valieron 120—; la primera edición de la obra completa de Baltasar Gracián (1664); y dos tomos de la Relación histórica del viaje de Jorge Juan y Antonio de Ulloa, infolios ilustrados con mapas. Las concienzudas anotaciones de los precios en estos y otros casos indicados informan, en fin, del gran valor que poseía el libro en ese momento en el contexto rural, distintivo de saber e instrumento necesario en el desarrollo personal y profesional de quienes los adquirían.

35 Tanto en el siglo XVIII como XIX Madrid copaba la producción en número de imprentas e impresos, seguida de Barcelona, que fue cobrando creciente importancia, a la vez que Valencia y Zaragoza —además de Sevilla—se mantenían como centros impresores importantes (Buiges, 2003: 304-307, y Botrel, 2003: 624-625).

36 Esta Biblia - que Ibarra editó en 1767 - no figura en el Catalogo del Servizio Bibliotecario Nazionale italiano, que recoge ediciones de los años 1731, 1741, 1748, 1755, 1757, 1760 y 1769; en el CCPB, aparecen también las posteriores de 1779 y 1797. 
Tabla 4. Clasificación geográfica editorial de la Biblioteca Membrado ${ }^{37}$

\begin{tabular}{|c|c|c|c|c|c|c|}
\hline Lugar de edición & S. XVI & S. XVII & S. XVIII & S. XIX & Total & $\%$ \\
\hline Madrid & & 2 & 20 & 21 & 43 & 41,3 \\
\hline Zaragoza & 1 & 5 & 6 & 1 & 13 & 12,5 \\
\hline Barcelona & & 1 & 4 & 5 & 10 & 9,6 \\
\hline Valencia & & & 5 & 4 & 9 & 8,6 \\
\hline Venecia & & 1 & 8 & & 9 & 8,6 \\
\hline Estrasburgo & 1 & & & & 1 & 0,9 \\
\hline Lyon & 1 & 5 & & & 6 & 5,7 \\
\hline Salamanca & & & 1 & 1 & 2 & 1,9 \\
\hline Pamplona & & & 2 & & 2 & 1,9 \\
\hline Ginebra & & [1] & & & 1 & 0,9 \\
\hline Roma & & & 1 & & 1 & 0,9 \\
\hline Calatayud & & & 1 & & 1 & 0,9 \\
\hline París & & & 1 & 1 & 2 & 1,9 \\
\hline Córdoba & & & & 1 & 1 & 0,9 \\
\hline Sin identificar & & & & & 3 & 2,8 \\
\hline & & & & & 104 & \\
\hline
\end{tabular}

\section{Conclusiones}

Recapitulando, la Biblioteca Membrado se formó con las aportaciones progresivas de distintos varones hasta llegar al cura Mariano, necesitados de libros para formarse y en su devenir laboral en torno al sacerdocio y la abogacía, además de algunas lecturas para entretener el tiempo de ocio. De este modo, en su parte esencial esos libros trazan un ciclo de lecturas desde la primera edad o del aprendizaje a la adulta social y profesional, para configurar una biblioteca eminentemente utilitaria de uso personal. Anotaciones y subrayados, puntos de lectura en el interior de las páginas u otros papeles escritos e incluso el deterioro de algunos ejemplares denotan ese uso, aunque es evidente, tal y como recuerdan los historiadores de las bibliotecas, que los libros poseídos no equivalen a libros leídos (Chartier, 1996: 37), lo mismo que, a la inversa, seguramente, los Membrado leyeron más libros que los propios. Asimismo, obtenidos por distintos medios, permiten vislumbrar distintos circuitos de lectura y usuarios previos como los carmelitas calandinos y otros profesionales del derecho, la medicina o la cura sacerdotal, igual que a escritores aficionados, es decir, a un pequeño círculo de letrados en un lugar alejado de los centros del saber y, en sus aledaños, a un público más amplio, espectador de representaciones sacras en las fiestas patronales o consumidor de pronósticos y remedios en lecturas compartidas.

Si bien varios Membrado eran conscientes de la posesión de un pequeño fondo bibliográfico propio, no albergaron la voluntad de configurar una biblioteca

37 Aunque los títulos impresos son 99, la cifra total se eleva a 104 al contar dos ediciones diferentes en tres de ellos: $\mathrm{n}^{\circ} 7,21,50$, este último en los dos volúmenes conservados. El $\mathrm{n}^{\circ} 12$ localiza el pie de imprenta conjuntamente en Madrid y Barcelona. 
familiar específica, resultante esta de la suma de los volúmenes que recabaron por separado. Así pues, se observa la lógica progresión temporal, con títulos más o menos contemporáneos a sus sucesivos propietarios — del XVIII y primera mitad del XIX—, que deja ver el peso decreciente del latín y de los autores extranjeros, paralelo al incremento de ediciones españolas. En lo temático, al hilo de las necesidades compartidas en estudios y profesiones, acaba resultando un conjunto homogéneo con una fisionomía bastante conservadora, tanto en las obras escolares —algunas editadas por religiosos - como en la filosofía tomista que imperaba en los estudios universitarios y, también, en los libros destinados al ejercicio pastoral. Sin embargo, aparecen ahí destellos de la Ilustración: Jorge Juan y Clavijo y Fajardo o ediciones comentadas y anotadas de la Biblia, entre las cuales la de Scío en castellano, y las obras de Almeida y Balmes, que apuntan a un catolicismo reflexivo. Es destacable, además, la presencia de otros temas, asociada a una intencionalidad práctica más allá de lo profesional y en varios sentidos: la voluntad de conectarse con la actualidad y los escenarios del mundo con las publicaciones periódicas y manuales para la vida social (desde las reflexiones ascéticas a los aforismos y los consejos de urbanidad), el aprendizaje de idiomas, la escritura de cartas o la aplicación de avances científicos a las explotaciones agrícolas. Se echan de menos los clásicos castellanos y éxitos literarios de los siglos XVIII o XIX, suplidos por algunas recopilaciones manuscritas destinada a los ocios privados, mientras que otras por encargo, en ejercicio de un paternalismo ilustrado o señorial, se destinaban a las fiestas de la comunidad que esta dinastía bajoaragonesa regía en lo político y en lo espiritual.

Esta biblioteca familiar dibuja, en fin, un interesante microcosmos libresco en una casona de Belmonte, entre barrancos amenos de olivos y pinares, sin duda similar al de otros señores rurales de entonces, vinculado todavía al cristianismo conservador pero atento al exterior contemporáneo. E informa del valor del libro, fuente de conocimiento, a la vez inversión de futuro y objeto de uso cotidiano, que en ese momento final de la Edad Moderna y comienzo de la Contemporánea permitió el ascenso y consolidación social de los Membrado.

\section{Catálogo de la Biblioteca Membrado ${ }^{38}$}

1. AA. VV., Autores selectos de la más pura latinidad anotados brevemente é ilustrados con algunas noticias de geografía, costumbres e historia romana para uso de las Escuelas Pías de la provincia de las dos Castillas y Andalucía, t. I, Madrid, Imprenta y

38 Cada entrada del inventario de Mur Gimeno consigna autor, título, lugar de edición, año y número de volúmenes; no están ordenadas como tampoco los ejemplares en los estantes. A partir de aquí y de la comprobación directa, realizo una ordenación alfabética por autores, añado editor o editorial, corrijo alguna autoría y otros datos, indico circunstancias de edición que puedan ser relevantes y trato de identificar los ejemplares incompletos en distintos catálogo: Biblioteca Nacional de España (BNE), Catálogo Colectivo del Patrimonio Bibliográfico Español (CCPB), Bibliothèque Nationale de France, British Library... Transcribo exlibris y anotaciones manuscritas. 
Fundición de D. Eusebio Aguado, 1845 (12 ${ }^{\mathrm{a}}$ ed.); t. III, Madrid, Imprenta de D. Leonardo Núñez de Vargas, 1828 ( $7^{a}$ ed.). ${ }^{39}$

2. AA. VV., Varios eloquentes libros recogidos en uno. Escrivieronlos diferentes autores, y los intitulados Retrato político del Señor Rey Don Alfonso el VIII [Gaspar Mercader y de Cerbellon]. El Perfecto Privado [Pedro Fernandez Navarrete]. Advertencias Políticas y Morales [Felix de Lucio Espinosa y Malo]. Jacinto Polo de Medina, Govierno moral a Lelio. D. Joseph Rubio, Gobierno moral a Fabio. El R. P. M. Fr. Juan Bautista Aguilar, Gobierno Moral à Lauro. Heraclito defendido, Filosofo que lloraba siempre los sucesos del Mundo [Antonio de Vieyra], Valencia, s.e., $1711 .^{40}$

3. Agustín de San Juan Bautista, Artificiosae Orationis sive Rhetoricarum Institutionum Epitome cui annectuntur Methodus Epistolaris, \& aditus ad Parnassum ex Tullio, Quintiliano, Camillo, Suspensio, aliisque probatis Auctoribus collecta auctore P. Augustino a S. Joanne Baptista, Clericorum Regularium..., Caesar-Augusta, apud Michaelem Montañes, 1730.

[Ms.] "Es de Joseph Membrado".

4. Alcober y Largo, Vicente, Método para aprender la lengua francesa, fundado en las leyes de etimología, analogía y onomatopeya, que presiden á la formacion de las lenguas, Madrid, Imprenta de M. Minuesa, 1857.

5. Almeida, Teodoro de, El hombre feliz, independiente del mundo y de la fortuna ó Arte de vivir contento en qualesquier trabajos de la vida. Obra escrita en portugués, segunda edición corregida y aumentada con Notas y Estampas por el P. D... de la Congregacion del Oratorio, t. III, Madrid, en la Imprenta Real, $1796 .{ }^{41}$

6. Arbiol, Antonio, Explicación breve de todo el sagrado texto de la doctrina christiana; para consuelo y aprovechamiento fundamental de las Personas espirituales, sacada de la quarta Impresion del Libro de los Desengaños Mysticos que compuso el P. Fr. ..., En Calatayud, Por Juan Aguirre, s.d. [entre 1762-1769].

[Ms.:] "Si este libro se perdiere Es de Mariano Membrado".

7. Arias y Acosta, Antonio Sandalio de, Lecciones de agricultura explicadas en la cátedra del Real Jardín Botánico de Madrid el año 1815 por don..., Madrid, Imp. que fue de Fuentenebro, 1816, 2 t. en 1 vol.

[Ms. en ambos tomos:] "M. G. de Bayo".

7 bis. Ídem, $2^{\mathrm{a}}$ ed. corregida y considerablemente aumentada por el mismo Autor, t. I, 1818.

8. Balmes, Jaime, El protestantismo comparado con el catolicismo en sus relaciones con la civilización europea, $5^{\mathrm{a}}$ ed., t. II, París, Librería de Rosa y Bouret, $1854{ }^{42}$

9. Benedicto XIV, Papa, De Festis Domini N. Jesuchristi et Beatae Mariae Virginis, Libri duo, Editio caeteris castigator, Madrid, Ex Typpographia Blasii Roman, 1778.

10. Benedicto XIV, Papa, Pastoral de nuestro Santísimo Padre Benedicto XIV, $6^{\circ}$ impr., t. I, Madrid, Benito Cano, 1789.

[Ms.:] “ex libris Joaquimi a Soro .... 14 rs von”.

11. Berault-Bercastel, Antoine-Henri de, ${ }^{43}$ Historia eclesiástica escrita en francés por el abad Berault-Bercastel, canónigo de la iglesia de Noyon, traducida en castellano y

\footnotetext{
Falta el t. II.

Recoge libros de diversos autores, cada uno con anteportada propia.

Faltan t. I y II.

Falta el t. I.

43 Tomo el título del t. IX; según el CCPB cambia a partir del t. III como: Historia eclesiástica / puesta en castellano por la que escribió en francés el Abad Berault-Bercastel enriquecida con notas por lo perteneciente a España, [por Lorenzo Hervas y Panduro]. En el lomo de cada volumen encuadernado en la Biblioteca Membrado figura como autor "Barruel”.
} 
aumentada con notas por lo perteneciente a España, Madrid, t. IX, X, XI, por Gómez Fuentenebro y Compañía, 1805; t. XII, ídem, 1806; t. XIII, Imprenta de D. José Collado, 1806; t. XIV-XV, Gómez Fuentenebro, 1806; t. XVI, XVIII, XIX, XXI, José Collado, 1806; t. XXII, XXIII, ídem, 1807; t. XXIV, XXV, ídem, $1808 .{ }^{44}$

12. Biografía eclesiástica completa, vidas de los personajes del antiguo y nuevo testamento; de todos los santos que venera la Iglesia, papas y eclesiásticos célebres por sus virtudes y talentos, en orden alfabético, redactada por una reunion de eclesiásticos y literatos..., Madrid, Imprenta y Librería de D. Eusebio Aguado; Barcelona, Imprenta y Librería de D. J. M. de Grau; t. I, 1848; t. II, 1849; t. III, 1850; t. IV, 1851; t. V, 1852; t. VI, 1853; t. VII, 1854; t. X, 1856; t. XI, 1857; t. XII, 1862; t. XIII y XIV, $1862 .{ }^{45}$

[Algunas hojas intonsas.]

13. Cano, Melchor, Melchioris Cani Opera Episcopi Canariensis, ex ordine praedicatorum, in duo volumina distributa, in hac primum editione clarius divisa, et praefatione instar Prologi Galeati illustrata, A. P. Hiacintho Serry..., Matriti, Ex Typographia Regia (vulgo de la Gazeta), 1774 , t. I. ${ }^{46}$

[Ms. autógrafo de Joaquín Soro] “Precio de este libro...... $16 \mathrm{r}^{\mathrm{s}}$ de vellón”. [en portadilla, con otra letra] "In usum Fracisci Soro empt..[?]/ hic fuit liber anno Domini 178[?]”.

14. Cervantes, Miguel de, Vida y hechos de D. Quixote de la Mancha, t. I, Barcelona, Juan Jolis, $1762 .{ }^{47}$

[Ejemplar incompleto, comienza en capítulo XXXIII y acaba en el XLIVI de la primera parte.]

15. Chevassu, Joseph, Misionero Parroquial ó Sermones para todos los domingos del año, Madrid, por Blas Roman; t. II, 1773; t. IV, $1785 .{ }^{48}$

16. Cicerón, Marco Tulio, M. Tullii Ciceronis Orationes selectae, tum libri De Senectute, de Amicitia \& Paradoxon, ad usum classis Rethorica, Caesar-Augustae, in Typographia Francisci Moreno, 1757.

[Ms. en guardas iniciales y finales extenso texto latino, garabatos en portada y márgenes pp. 3 y 5, y un dibujo infantil de un monigote en p. guarda final]. "R..., Membrado,/

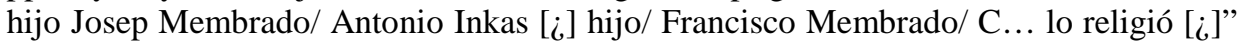
[en la tapa final].

17. Cicerón, Marco Tulio, M. Tullii Ciceronis, et nonnullorum optimae latinitatis recentiorum orationes selectae ad usum scholarum, Caesaraugustae, in Officina Nosocomii Beatae Mariae Virginis de Gratia, 1816.

[Ms.:] "Si este libro se perdiere, como puede suceder ruego a quien le allase si me lo quiere bolver si mi nombre no se supiese al fin de este verso lo allan [...] tengo por nombre Ramon para poderte servir Trullenque por sobrenombre para con Cristo morir/ Ramon Trullenque”.

18. [Clavijo y Fajardo, José de,] El Pensador Matritense. Discursos criticos sobre todos los asumptos que comprehende la sociedad civil, Barcelona, Por Francisco Generas Impresor, s.d. [c. 1780], 5 t.

44 Faltan los t. I-VIII, XVII y XX.

45 Faltan t. VIII, IX y XV-XXX. Obra completa editada en 1848-1868: los t. XIII-XXX, impresos por Alejandro Gómez Fuentenebro; del t. XV al XXX la obra está bajo la dirección del Sr. Basilio Sebastián Castellanos de Losada (CCPB).

46 Falta el t. II.

47 Edición completa en 4 vols. Según Gabriel Sánchez Espinosa, a quien debo su identificación, puede corresponderse con la $2^{\mathrm{a}}$ ed. de una de 1755 , difícil de distinguir de la $1^{\mathrm{a}}$.

48 Faltan t. 1 y 3 . No he localizado ninguna edición de 1773 en la BNE o en el CCPB. 
[Ms. t. tercero:] "Juan Pío Membrado”.

19. Concina, Daniele, Theologia Christiana dogmatico-moralis, Romae, apud Simonem Occhi, 1763, 10 t. en 6 vols.

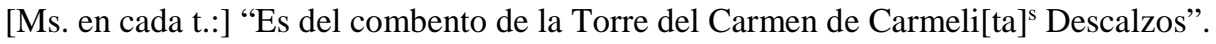
Cortés, Jerónimo, El Non plus ultra de el Lunario y pronostico perpetuo general y particular para cada reyno y provincia, compuesto por don ...; expurgado segun el expurgatorio del año 1707 de la Santa Inquisicion y aora nuevamente reformado y añadido por don Pedro Enguera, professor de Mathematicas, Barcelona, en la imprenta de María Angela Martí Viuda, 1760.

[Ms. guarda:] "Si este libro se perdiere como puede suceder manifiéstenlo a Joaquin Bidal/ Isabel Vidal... Conchello/ D. Joaquin Vidal menor/ Vicente Vidal Mayor/ Pedro Vidal/ a Vicente Vidal menor/ Benito Vidal maior/ Mariano Vidal menor”. [reverso portadilla] "Compro Joaquin Bidal a Cosme pique el año 1783 por 2 reales de plata./ Migel Navarro deve a mi anvel [sic] Sanz ... por coxines $4 \ldots$ pesetas $9 \ldots$ [ilegible]”. Contiene tiras marcadoras de páginas, fragmentos de apuntes, un dibujo, una estampa religiosa grabada.

20. Cortés, Jerónimo, Fisonomía y varios secretos de naturaleza, Barcelona, Por Joseph Giralt, s.d. [post. 1741].

[Ms.:] "Si este libro se perdiere suplico al qe se lo allare si me lo puede Bolber qe es de Francisco Navarro Yo lo ... en velmonte en el ano 1817 ... [texto incomprensible]”.

21bis. Otro ejemplar incompleto, que comienza en p. 7; distinta ed.

21. Cuniliati, Fulgenzio, Universae Theologiae Moralis... A. P. F. Fulgentio Cuniliati Ordinis Praedicatorum, 8 ${ }^{\mathrm{a}}$ ed., Venetiis, apud Thomam Bettinelli, 1777.

[Ms.:] “Alter ex anumeratis inter libros M. Georgii Ariño et Ripot.”/ [otra letra] "Nunc autem ad Mariani de Membrado libris pertinet”.

22. D. y Begas, J. Antonio, Nuevo estilo y formulario de escribir cartas misivas y responder á ellas en todos géneros de correspondencia reformado según el estilo moderno y añadida en esta última edición, Barcelona, Por Juan Francisco Piferrer, 1835.

23. Danes, Peter Ludwig, Institutiones doctrinae christianae sive Compendium theologiaae dogmaticae \& moralis... auctore Petro Ludovino Danes, t. I, Venetiis, ex Typografia Balleoniana, $1733 .^{49}$

24. Devota novena en festiva celebridad del feliz glorioso tránsito y asunción de la Santísima Virgen María... De $N^{a} S^{a}$ de la Seo, vulgo del Milagro... Valencia, 1834, Imprenta de don Benito Monfort.

25. Diana, Antonino, Resolutionum moralium pars prima, et secunda..., $3^{\mathrm{a}}$ ed., Caesaraugustae, apud Iacobum Dormen, 1632.

[Ms.:] "Este libro es de ... [tachado]".

Díaz de Guereñu, Pedro, Año Panegyrico, ó sermones escogidos panegyricos para los principales mysterios de Jesu Christo ... y Festividades de su Santisima Madre y Santos ... repartidos por los meses del año..., por... Don..., t. I, Madrid, Por Pedro Marín, $1785 .{ }^{50}$

[Ms.:] "Soy de Benito Ernicas".

26. Discvrso primero en los svcessos de la Imperial Civdad de Çaragoça, cabeça de la Corona de Aragon, sv origen y principio [sin identificar: siglo XVII]. ${ }^{51}$

Falta el segundo tomo.

Obra completa: 6 tomos.

51 El autor comienza proclamándose extranjero: "verdades que en mi pluma, por estrangera, pareceran menos apasionadas". 
[Faltan portada y datos de edición. 236 pp.]

27. Du Hamel, Jean-Baptiste, Biblia Sacra Vulgatae Editionis... annotationibus, prolegomenis, Tabulis Chronologicis, Historicis \& Geographicis illustrata, Jo. Baptista du Hamel... et Josephi Blanchini, Venetiis, Ex Typographia Balleoniana, 1759, 2 t.

[Ms. en cada tomo:] "De Mn. Joaquin Soro $=1^{\circ}$ y $2^{\circ}$ thomo. $72 \mathrm{r}^{\mathrm{s}} \mathrm{v}^{\mathrm{on} . ” / “ \mathrm{De}}$ Mariano Membrado”.

28. Dubroca, Jean François, Conversaciones de un padre con sus hijos sobre la Historia Natural, ... por ..., y traducida al castellano por D. Manuel María de Ascargorta y Ramirez, t. III, Madrid, en la Imprenta que fue de Fuentenebro, $1815 .^{52}$

[Ms. guarda:] “Natural de/ Belmonte/ Belmonte [rubricado]”. Está entrecruzado con: "Pacíficamente tus latrocinios/ Pero como es se q $q^{\mathrm{e}}$ las permite ejercer/ y demas/ Alguna veo la cuestan bien caro todas/ sus abilidades".

29. Duchesne, Jean-Baptiste, Compendio de la Historia de España escrito en lengua francesa por el P..., traducido al idioma español para la de la noble juventud española, por el P. Antonio Espinosa, t. II, Madrid, Manuel Fernández, 1749. ${ }^{53}$

30. Eguileta, Joaquín Antonio de, Pláticas doctrinales o explicación de toda la doctrina christiana, $2^{\mathrm{a}}$ ed., Madrid, en la oficina de Don Gerónimo Ortega y Herederos de Ibarra, 1802, 3 t.

31. Escosura, Patricio de la, Manual de mitología, compendio de la historia de los dioses, héroes y más notables acontecimientos de los tiempos fabulosos de Grecia y Roma... por..., Madrid, Estab. Tip. de F. de P. Mellado, Editor, 1845.

[Faltan pp. iniciales hasta la 7.]

32. Escriche, Joaquín, Elementos de Derecho Patrio, Madrid, Impr. del Colegio Nacional de Sordo-Mudos, 1838.

[Ms.:] “J. P. M.” y “J. B. [rubricado]”.

33. Febrero, Josef, Febrero reformado o librería de escribanos, que compuso...; y ha reformado en su lenguage, estilo, método y muchas de sus doctrinas ... el lic. D. Joseph Marcos Gutierrez, Madrid, en la Imprenta de Villalpando, Parte t. I, 1801; Parte II, t. V, 1802. ${ }^{54}$

34. Fernández de Ayala Aulestia, Manuel, Práctica y formulario de la Real Chancillería de Valladolid, que recogió y compuso... reimpressa con methodo mas claro... por Don Joseph de Luiando, Zaragoza, por Francisco Revilla, 1733.

35. Fernández de Velasco y Pimentel, Bernardino, Deleyte de la discreción y facil escuela de la agudeza, que en ramillete texido de ingeniosas promptitudes y moralidades provechosas... los recogio el Exmo. Sr. D. ..., Madrid, en la oficina de Gabriel Ramirez, 1749.

36. Fisices Comentaria Justa Methodis Valentiae Universitas digesta In duas Partes Preposita atq ${ }^{e}$ Virgini et Matri Maria ab omni culpe libera dicata, inquoata, Die $12^{\circ}$ februari Anno 1745, Fisica seu Philosofie Natis Argutd. [?]”, ms. sin paginar, varias caligrafías.

37. Foderé, François-Emmanuel, Las leyes ilustradas por las ciencias físicas ó Tratado de medicina legal y de higiene pública, escrito en Frances por el ciudadano ...; y traducido por J. D. R. y C., Madrid, t. II y V, en la Imprenta de la Administración del Real Arbitrio de Beneficencia, 1801; t. VI, en la Imprenta Real, 1802. ${ }^{55}$

\footnotetext{
Obra completa: 4 tomos editados en 1802-1803.

Falta el t. I.

Obra completa: 5 tomos editados en 1801-1802.

55 Obra completa: 8 tomos, editados en 1801-1803.
} 
38. Frey de Neuville, Charles, Sermones del P. Carlos Frey de Neuville, predicador de Luis $X V$, rey de Francia, traducidos del francés por D. Juan Antonio Pellicer, de la Real Biblioteca, Madrid, por don Blas Román; t. III, “Quaresma”, 1789; t. IV, “Quaresma”, 1793. ${ }^{56}$

39. Fueros y observancias del reyno de Aragon, Bartolomé Leonardo de Argensola (ed.), En Çaragoça, por Pedro Cabarte, impressor y librero de dicho Reyno de Aragón, 1624.

40. Galmace, Antonio, Llave nueva, y universal para aprender con brevedad, y perfección la lengua francesa, París, s.e., 1753.

[Ms.:] “Alter ex libris Francisci Soro”.

41. García, Juan Justo, Elementos de aritmética, álgebra y geometría, $3^{\mathrm{a}}$ ed., t. II, Salamanca, en la oficina de Francisco de Tóxar, $1801 .^{57}$

[Ms. en portada:] “Alter inter libros Mariani a Membrado”/ “Mariano Membrado”, [en reverso] "Zaragoza/ Ex libris Mariani Membrado y Soro/ Seminario Conciliar”. [Tachados otros nombres en guarda.]

42. Godefroy, Denis, Corpus iuris civilis a Dio. Gothofredo, $4^{\mathrm{a}}$ ed., s.l. [Ginebra], Ex Typographia Iacobi Stoer, 1625, 2 t.: tomus I continens Pandectarum seu Digestorum libros quinquaginta; tomus II Codicis D. N. Iustiniani libri XII, etc.

[Ms.:] “D. Greg' Lemendian [?]”.

43. [Gómez de Barreda, Ínigo,] Las fantasmas de Madrid y estafermos de la Corte, obra donde se dan al publico los errores y falacias del trato humano, para precaucion de los incautos: excitada de algunos discursos del Lustre de nuestra España y Religion Benedictina el Ilustrissimo y Reverendissimo Feijóo sobre algunos otros errores comunes, su autor El Desengaño...; sacale a luz don Ignacio de la Erbada, Salamanca, Por Antonio de Villagordo y Alcaraz, t. II [1761]; t. III [1762]; t. IV, 1763. ${ }^{58}$

44. Gonet, Jean-Baptiste, Manuale Thomistarum seu brevis theologiae cursus ..., Lugduni, Sumptibus Anissoniorum \& Ioan. Posuel et Henrici Martel, t. VI, 1680; 3ª ed., t. I, 1690.

[El t. I, en mal estado, carece de portada. ${ }^{59}$

45. Gonet, Jean-Baptiste, Clypeus Theologiae Thomisticae ..., $6^{\mathrm{a}}$ ed., Lugduni, apud Anissonios \& Joan Posuel, 1681, 4 t. ${ }^{60}$

[Ms.:] “Carmelitarum Discalceadorum Turritanorum”.

46. Gotti, Vicentium Ludovicum, Theologia Scolastico-dogmatica, iuxta mentem divi Thomae Aquinatis ad usum discipularum, Venetiis, Ex Typographia Ballenoniana, 1781, 3 t.

[Ms. en cada tomo:] “Ad usum Joaquimi â Soro Scolastici Theologia in Cibitate Cesaraugustana” [remate con dibujo de un ciprés, t. I y III]; en tomus secundus, debajo, mismo exlibris con ornamentos, oración latina y cuentas; en tomus tertius, "Los tres tomos costaron $120 \mathrm{r}^{\mathrm{s}} \mathrm{v}^{\mathrm{n}}$ ".

47. Gracián, Baltasar, Obras de Lorenzo Gracian... Ultima impression mas enriquecida y corregida de tablas, Madrid, por Pablo de Val a costa de Santiago Martin Redondo, 1664, 2 t.: t. I: El Criticon, El Oraculo y El Heroe; t. II: La agudeza, y arte de ingenio,

56 Obra completa en varios tomos, correspondientes a periodos litúrgicos, editados en imprentas y fechas diferentes.

57 Falta el t. I.

58 Falta el t. I. Las fechas de los t. II y III están tomadas de la aprobación y licencia. En cuanto a la autoría, el catálogo de la BNE remite a Rogers y Lapuente (1977), para quienes el seudónimo "El Desengaño" se corresponde con quien firma: Ignacio de la Erbada, y a Aguilar Piñal (Bibliografía, IV, n 155), que cree que este nombre es el anagrama de Iñigo Gómez de Barreda.

59 Edición completa en 6 tomos.

60 Faltan t. V y VI. 
El Discreto, El Politico Don Fernando el Catolico, Meditaciones varias para antes y despues de la sagrada comunion.

48. Guevara y Basoazábal, Andrés de, Institutionum Elementarium Philosophiae ad usum Studiosae iuventutis, ab ... Guanaxuatensi Presbytero, t. III, Physicam generalem, y t. IV, Physicam particularem, Valentiae, in Officina Idelphonsi Mompié, $1824 .{ }^{61}$

[Tres ejemplares del t. III, con anotaciones mss.:] 1) “De Mariano Membrado"; 2) "Soy de José Ruiz este tomo, junto con los otros tres, cuestan 14 pesetas”; 3) [otra ed.] Matriti, Ex Typographia Regia, 1829.

[Cuatro ejemplares del t. IV, con anotaciones mss.:] 1) “Soy de Mariano Membrado, Natural de Belmonte, partido [?] de Alcañiz, diócesis de Zaragoza. Habita en la calle des [...] Cruz, casa sin número”; 2) "Dn. Mariano Membrado, natural de Bello monte”/ [series numéricas]/ "Mariano Membrado [con rúbrica]”/ "Dn. Enrique Belsa/ Dn. Geronimo Latorre de Iraosidia? / Dn. Escolástico Aparicio// Dn. Cristóbal Martínez”; 3) "Ruyz"; 4) [otra ed.] Matriti Ex Typographia Regia, 1829, "Para el uso de Pedro Espallargas. Año de 1830”/ “1832 [rubricado]”.

49. Gutiérrez, José Marcos, Práctica criminal de España, Publicala el Licenciado Don Josef Márcos Gutierrez, editor, del Febrero reformado y anotado, para complemento de esta obra que carecia de Tratado Criminal..., t. II, Madrid, en la Oficina de don Benito García y Compañía, 1805. ${ }^{62}$

50. Homedes, Isidoro, Quaderno $3^{\circ}$ de las obras del Ldo. $D^{n}$. ..., Año 1764, [Belmonte], ms., 164 pp. numeradas en $\mathrm{r}$.

[Contiene índice con 24 composiciones (una loa, dances, gozos, villancicos, un coloquio y un auto sacramental, dedicados a santos y advocaciones marianas de la comarca).]

51. Huerta, Antonio, Cuaderno en donde se allan varios papeles para el uso de Antonio Huerta en Ainzon, ms., sin paginar, s.d. [siglo XVIII].

[Título encabezado por "Soy de Antonio Huerta”, seguido de su firma rubricada. Contiene diversas composiciones, la mayoría en verso: "De las octavas de las quatro partes del Mundo y de la España”, “Memorial de Dn Eusebio Vergara Pro. al Exmo Sr Arzovispo de Toledo con motivo de deber a S Excelencia 6000 reales y no tener con qe pagarlos”, Letrillas satíricas, "Paralelo entre Homero y Cervantes” (en prosa), etc.]

52. Hugo de San Caro, Beato, Sacrorum Bibliorum Vulgatae editionis Concordantiae Hugonis Cardinalis Ordinis Praedicatorum..., recensitae atque emendatae: primus à Francisco Luca Theologo... postea variis locis expurgatae, ac locupletata cura \& studio U. D. Huberti Phalesii, Ordinis Sancti Benedicti, Venetiis, apud Nicolaum Pezzana, 1754.

53. Jacquier, François, Institutiones Philosophicae. Adstudia Theologica potissimum acomodatae, Venetiis, Simonis Occhi curis, 1770, 6 t., 4 vols.

[Ms. t. tertius y quintus:] “Alter ex anumeratis inter libros Francisci Soro [rubricado]/ Membrado [rubricado]/ Membrado [repetido en t. quintus].”

54. Juan, Jorge, Relación histórica del viage a la América Meridional hecho de orden de S. Mag. para medir algunos grados de meridiano terrestre... por don ... y don Antonio de Ulloa..., "Segunda parte”, t. III y IV, Madrid, por Antonio Marín, 1748. ${ }^{63}$

55. Juan y Colom, José, Instrucción de escrivanos en orden a lo judicial, utilissima también para procuradores y litigantes ..., tercera impresión, Madrid, en la Imprenta de la Merced, 1747.

\footnotetext{
61 Obra completa: Valencia, 5 tomos.

62 Obra completa: 3 tomos editados en 1804-1806.

63 Falta la "Primera parte", que abarca los tomos primero y segundo.
} 
56. Juanes, José, Juicio sobre los derechos producidos por la ley que suprimió las vinculaciones, Valencia, Imprenta de José de Orga, 1847.

57. Lamberto de Zaragoza, Teatro histórico de las iglesias del Reyno de Aragón, t. IV, Pamplona, Imprenta de la viuda de Joseph Miguel de Ezquerro, $1785 .{ }^{64}$

58. La Ripa, Juan Francisco, Ilustracion a los quatro processos forales de Aragon: orden de proceder en ellos, según el estilo moderno; y reglas para decidir conforme à la naturaleza de cada uno, Zaragoza, en la Imprenta de Francisco Moreno, 1764.

[Ms.:] "Soy de [ilegible] y me costo \#56 $\mathrm{r}^{\mathrm{s}} \mathrm{v}^{\text {on" }}$. [Debajo] "Soy del Presbitero dn. Manuel Suñer Abogado de los Reales Consejos”.

59. Legouas, F. V., Nuevos principios de cirujía, Madrid, Imprenta de calle de la Greda, 1826.

Ms.: "Para el uso de José Trullenque. Nuebos principios".

60. Lista, Alberto, Elementos de Matemáticas puras y mixtas, $2^{\mathrm{a}}$ ed., t. I, Madrid, Imprenta de D. León Amarita, 1823. ${ }^{65}$

61. Madalena, Tomás, Tyrocinium Morale Pro Scholasticis... a M. Fr. Thoma Madalena, Caesar-Augustae, t. I, apud Haeredes Emmanuelis Roman, Universit. Typographi, 1726; t. II, apud Petrum Ximenez Typographum, 1728.

[Ms. t. I:] "Franc ${ }^{\circ}$ Soro [rubricado], Nat' de Fozcalanda”/ [otras anotaciones:] "Dn Juan Antonio/ Dn Nicolas/ Dn Pasqual Guerri/ Zaraga” [cuentas, un dibujo].

62. Marchant, Jacques, Hortus Pastorum Sacrae Doctrinae Floribus Polymitus autore R. D. Jacobo Marchantio, Lugduni, apud Anissonios, Ioan. Posuel \& Claud. Rigaud, 1689.

63. Martín y Fernando, Mariano, Curso completo de música vocal y elementos de Piano y órgano, Zaragoza, Imprenta de D. Calisto Ariño, 1861.

[Ms.:] "No 6, $2^{\circ}$ Curso/ $\mathrm{P}^{\mathrm{n}} \mathrm{Ant}^{\mathrm{o}}$ Serret./ Mar ${ }^{\circ}$ Martín [rubricado].”

64. Martos y Román, Joaquín de, Tratado nuevo de enseñanza del arte de agrimensor ó ciencia de medir y partir tierras por D. ..., Córdoba, Establecimiento Tipográfico de D. Fausto García Tena, 1846.

65. Mazzota, Nicolai, Theologia Moralis, t. V, Venetiis, Ex Typographia Remondiniana, $1760 .^{66}$

66. [Medici, Paolo Sebastiano], Ritos y ceremonias de los hebreos confutados..., obra traducida del italiano al castellano por el Padre Fray Juan de Lidon..., t. III, Madrid, Oficina de D. Benito Cano, $1800 .^{67}$

[Ms. y tachado:] “Doct. Josephi â S... A. Bellido/ [otra línea ilegible]”.

67. Mercurio histórico y político, que contiene el estado presente de la Europa, lo sucedido en todas las Cortes... mes de agosto de 1759. Con reflexiones políticas sobre cada Estado, Madrid, en la Imprenta de Antonio Marín, 1759.

68. Molina, Luis de, De Hispanorum Primogeniorum Origine ac Natura libri quatuor, authore Ludovico de Molina, Lugduni, 1588.

69. Molina, Luis de, Additiones sev illustrationes aureae ad D. Ludovici de Molina Celebrem Tractatum De Hispaniarum Primogeniis, [Lugduni, Iacobum Prost, 1634]. ${ }^{68}$

70. Nebrija, Elio Antonio de, De Institutione Grammaticae [sin identificar: ed. s. XIX]. [Faltan las páginas iniciales.]

\footnotetext{
64 Obra completa: 9 t., 1780-1807, con distintos pies de imprenta a partir del V.

65 Obra completa: 4 tomos, editados en 1823-1825.

66 Obra completa: 5 t.

67 Obra completa: 3 t.

68 Datos procedentes del privilegio de impresión.
} 
71. Nicolas, Auguste, Del protestantismo y de todas las herejías en su relación con el socialismo, precedido del exámen de un escrito del Sr. Guizot por Augusto Nicolás, Barcelona, Librería Religiosa, Imprenta de Pablo Riera, 1853.

72. Oliver, Vicente María, Explicación histórica, moral y mística de la sequencia del Santissimo Sacramento, su autor el R. P. M. Fr. ..., sacala a la luz Don Carlos Assins de Oliver, t. I, Valencia, en la Oficina de Joseph Garcia, 1738.

[Ms.:] "El Cura Zirujeda de Esta Librería tiene tres tomos de la Estrella del Alva, el Incógnito./ Mn. Miguel Cortés tiene Pláticas de Estevez, y los q. el dirá [?]/ Fr. Mathias Jayme Florez Clave Historica, y el Pe Pinamonte”. [Debajo, con distinta letra:] "Es de Joaquin Soro/ de Fozcalanda/ Partido de Alcañiz/ Diocęsi de Zaraga".

73. Ovidio Nasón, Publio, P. Ovidii Nasonis Metamorphoseon Libri XV. Index repertorius omniu Fabularum, ad numero chartarum \& seriem Alphabeti, Argentorati, excudebat Ioannes Knoblochus, 1525.

[Ms.:] "De Gabriel Piquero de la Vega” / "Del Pro.? Fran ${ }^{\text {co }}$ Pérez Perea 28 7bre de 1770”. [Subrayados, anotaciones y traducciones al margen.]

74. Patuzzi, Giovanni Vincenzo, Ethica christiana sive theologia moralis, t. II, Bassani, prostant Venetiis apud Remondini, $1794 .{ }^{69}$

75. Pérez y Gascón, Pascual, Principios de solfeo y canto para uso de los alumnos del Colegio Real de San Pablo de Valencia, 4 ed., Valencia, Imprenta de José Rius, 1857. [Ms.:] "Juan Pío Membrado”.

76. Pérez Morga, Felices, Coleccion de Reales Cédulas, instrucciones, órdenes y demas disposiciones del ramo de pósitos hasta fin del año de 1826: con algunas notas instructivas para mayor ilustracion, Madrid, en la Imprenta Real, 1827.

77. [Pars $1^{a}$ ] Phile. Ratis que sumulas nuncupatur [contiene Index Librorum Questionem et Articulorum in Partem Racionalem]/ Pars $2^{a}$ Philosophie Rationalies/ Pars 3 Phile. Rationalis.... Ms., 198 pp. numeradas en anverso.

[Anotación en p. de cortesía:] "Matias Buisan”.

78. Pintón, José, Compendio histórico de la religión, $12^{\mathrm{a}}$ ed., t. II, Pamplona, por la Viuda de Ezquerro, $1784 .^{70}$

[Ejemplar sin portada ni pp. 1-2; comienza en cap. quinto.]

[Ms.:] "Cosme Membrado. Natural de la billa de Belmonte".

79. Planas, Juan, El catequista orador ó El catecismo romano dispuesto en pláticas doctrinales en obsequio de los señores párrocos, $2^{\mathrm{a}}$ ed., t. I, Barcelona, Impr. de los Herederos de la Viuda Pla, $1857 .^{71}$

80. Portolés, Jerónimo, Tertia [-quarta] pars scholiorum sive Adnotationum ad repertorium Michaelis Molina, super foris et observantiis regni Arago, authore Hyeronimus Portoles, Caesaraugusta, per Laurentium de Robles, Regni Aragonum Universitatis Tipographum, $1590 .^{72}$

81. Possevino, Giovanni Battista, De officio curati, ad praxim, praecipue circa repentina \& generaliora liber Ioannis Baptistae Bernardini Posseuini...; hac nouissima editione emendatus, authoris additionibus, notisque Andreae Victorelli...; Accessere Sacrae Congregationis ad nonnulla Concilij Triden. capita de matrimonio declarationes...; ta[n]de[m] \& noua collectanea pro Bulla Coenae D. illustratus, Barcinone, apud Sthephanum Liberos, sumptibus Michaelis Gratiani, 1620.

[Ms.:] "De los Carmelitas Descalzos de la Torre”.

69 Falta el tomo primero.

70 Falta el primer tomo.

71 Falta el tomo segundo.

72 Aparecen otras fechas: 1591 en el colofón de la segunda parte y 1592 en el pie de imprenta de la cuarta. 
82. Pracsim Dispuntandi Prescribit. Ms. con distinta letra; sin paginar, sin portada, comienza en continuación del capítulo 3: Caput 3um.

[Anotaciones en fragmento de p. de cortesía:] “Jaenîn Mîr Mariano/ Bosce/ Brionzem [¿ं Membrado/ Manel Bosce/ En Madrid se alara en la înprenta y liberîara [sic]/ Sn. Pero apostolo capitulo de Tarragona”.

83. Proemium/ Questio Proemialies de nata fisice. Ms. con misma letra que $\mathrm{n}^{\circ} 79$, que continúa [colofón: “finis utriusque Partis filosofie rat[ional]is. et naturalis”]; sin paginar, con letras capitales y títulos destacados; retrato al final de San Vicente Ferrer con la leyenda “Timete Deum Illi Honorem”.

84. [Raisson, Horace], El hombre fino ó Manual completo de urbanidad, cortesia y buen tono... Traducción del francés al castellano por Don Mariano de Rementería y Fica, $3^{\mathrm{a}}$ ed., Madrid, Imprenta del Colegio de Sordo-Mudos, 1837.

85. Ramón, Guillermo, Catechismi romani expositio variis praelectionibus secundum novam methodum tam in dioecesi toledana, quam in aliis hispaniarum, et indiarum praescriptam, t. II, Sacramenta complectens, Matriti, apud Hieronymum Ortega et filios Ibarra, $1789 .^{73}$

86. [Richard, Jean], ${ }^{74}$ Elogios históricos de los santos, con los misterios de nuestro Señor Jesu Christo, y festividades de la Santísima Virgen, para todo el año, traducidos del francés por D. Francisco Antonio Perez presbitero, t. III, Valencia, en la Oficina de Joseph y Thomas de Orga, $1780 .{ }^{75}$

87. Salas, Petri de, Compendium Latino-Hispanum utriusque Linguae Veluti Lumen, Barcinone, Ex Typographia Conjugem Sierra \& Martí, 1800.

[Ms.:] "De M $\mathrm{M}^{\mathrm{n}} \mathrm{Joaq}^{\mathrm{n}}$ Soro $.28 \mathrm{r}^{\mathrm{s}} \mathrm{v}^{\mathrm{on}}$ ”.

88. Sánchez Sobrino, Sebastián, Sermones vespertinos ó de misión, t. X, Madrid, por la Viuda de Barco López, 1806. ${ }^{76}$

89. Santana Bustillo, Lorenzo de, Govierno político de los pueblos de España y el corregidor, alcalde y juez en ellos, Zaragoza, en la Imprenta de Francisco Moreno, 1742.

90. Santo Tomás, Manuel de [Traggia], Verdadero carácter de Mahoma y de su religión: justa idea de este falso profeta sin alabarle en exceso ni deprimirlo con odio... que escribia en defensa de la verdadera religion catolica, el P. Fr. ..., Valencia, en la Imprenta de Francisco Burguete, 1793-1795. ${ }^{77}$

[Ms.:] "De M" Joaquín Soro".

91. Scío de San Miguel, Felipe, La Biblia Vulgata latina traducida en español, y anotada conforme al sentido de los Santos Padres y expositores cathólicos..., En Valencia, en la oficina de Joseph y Thomas de Orga, 1790-1793, 10 t.: t. I y II, Nuevo Testamento (1790), t. I, II y III, Antiguo Testamento (1791); t. IV y V Antiguo Testamento (1792); t. VI, VII y VIII, Antiguo Testamento (1793).

92. Sessé, José de, Decisionum Sacri Senatus Regii Regni Aragonum et Curiae domini Iustitiae Aragonum causarum ciuilium \& criminalium... authore F. Iosepho de Sesse, Caesaraaugustae, t. I y II, apud Ioannem à Lanaja \& Quartanet, 1615; t. IV [Juan de Larumbe, 1624].

Falta el tomo primero.

Omitido el autor, que figura en el prólogo (CCPB).

Obra completa: 4 tomos.

Obra completa: Sermones varios (panegiricos y morales... de Quaresma...), 1800-1819, 20 t.

77 Contiene 4 partes en 1 vol. con sendas anteportadas: "Discurso preliminar..." (1793), "Primera parte, que trata de la vida de este legislador... (1794), $2^{\text {a }}$ parte: Justa idea de este falso profeta sin alabarle en exceso ni deprimirle con odio (1794), $3^{\mathrm{a}}$ parte (1795). 
[Ms.: t. I y II] "Ex libris Alexandri Ferrer Virginy anno a Partis [?] 1696”; [con otra letra, t. I] "Manuel Ceperuelo, abogado de Castelseras, los años primeros del [...] 19 tenia este libro".

93. Suárez de Ribera, Francisco, Cirugia Methodica. Chymica reformada, Madrid, a costa de Francisco Laso, 1722.

94. Suárez de Ribera, Francisco, Remedios de Deplorados, probados en la piedra, lydio de la experiencia, Madrid, en la Imprenta de Alonso Balvás, 1732.

[Ms.:] "Este libro es de Antonio Nogueras, practicante en el Santo Hospital. Lo compro de Paulino Gil, le costó $24 \mathrm{r}^{\mathrm{s}} \mathrm{v}^{\mathrm{n}}$ ”.

95. Swieten, Gerard van, Descripción compendiosa de las enfermedades más comunes del exercito, con un nuevo, facil y seguro methodo de curar el mal venéreo... traducido al castellano por D. Agustin Arguello y Castrillo, y añadido con algunas notas y muchas advertencias para los Cirujanos de mar, Madrid, en la Imprenta de Joaquin Ibarra, 1761.

[Ms.:] “Ex libris D". Michaelis Pardos 1765” [con motivo vegetal coloreado].

96. Tabla de los secretos de naturaleza [sin identificar].

[Título según el índice de este libro, del que faltan portada y los 3 primeros capítulos.]

97. Tamayo Salazar, Ioanne, Anamnesis sive commemorationis Sanctorum Hispanorum, Lugduni, Philip Borde, Laurent Arnaud \& Cl. Rigaud; t. II, 1652; t. IV, 1656; t. V, $1658 .^{78}$

98. Tomás de Aquino, Santo, Divi Thomae de Aquino... Quaestiones quodlibetales duodecim, Venetiis, apud Juntas, 1612.

99. Torío de la Riva y Herrero, Torquato, Arte de escribir por reglas y con muestras, según las reglas de los mejores autores antiguos y modernos, extrangeros y nacionales, acompañados de unos principios de Aritmética, Gramática y Ortografía castellana, Urbanidad..., Madrid, en la imprenta de la viuda de Don Joaquin Ibarra, 1798.

100. Torre y Ocón, Francisco de la, El maestro de las dos lenguas. Diccionario español y francés, francés y español, Madrid, en la imprenta de Juan de Aritzia, 1728-1731, 2 t.

[Ms. t. II:] “Mariano Membrado".

100 Torrente, Mariano, Hic tractatus Metaphysicae dictatus et edoctus fuit à D. D. Mariano à Torrente, in alma Academia Caesaraugustana, ms., paginado hasta p. 141rv, s.d.

[Título e índex al final. Anotación: "Dn Joseph Matheo [rubricado]/ Ahora de Ramon Valles".]

101 Villalobos, Enrique de, Summa de la Theologia Moral y Canonica, Zaragoza, por la Viuda de Pedro Verges, 1646.

102 Wigandt, Martin, Tribunal Confessariorum et ordinandorum, Pisauri sed prostat Venetiis, apud Nicolaum Pezzana, 1760.

103 Zurita, Jerónimo, Los cinco libros primeros de la segunda parte de los Anales de la Corona de Aragón compuestos por Geronimo Zurita, cronista de dicho reyno, t. III, Zaragoza, por los Herederos de Pedro Lanaja y Lamarca, $1669 .{ }^{79}$

78 Obra completa: 6 t. editados en 1651-1659.

79 La obra completa consta de 7 tomos, impresos entre 1668-1671, algunos por Diego Dormer. Estuvo entera en la Biblioteca Membrado, de donde pasó a manos de la viuda de Joaquín Mur Estevan, uno de los herederos.

Ramón, hermano de este, compró el tomo III. 


\section{Referencias bibliográficas}

Archivo Membrado, Bellmunt de Mesquí.

Barrio Gozalo, M. (2010). El sistema beneficial de la Iglesia española en el Antiguo Régimen (1475-1834). San Vicente del Raspeig: Ediciones de la Universidad de Alicante.

Benedicto XIV (1791). Colección en latín y castellano de las bulas, constituciones, encyclicas, breves y decretos del Santísimo Padre... Madrid: en la oficina de Antonio Espinosa

Bécares Botas, V. (1999). Las bibliotecas monásticas y la desamortización en la provincia de Zamora. Zamora: Semuret.

Bolufer Peruga, M. (2002). Pedagogía y moral en el siglo de las luces: las escritoras francesas y su recepción en España. Enseñanza y vida académica en la España Moderna. Revista de Historia Moderna. Anales de la Universidad de Alicante, 20, 5-109.

Botrel, J.-F. (2003). El «movimiento bibliográfico», en Infantes, V.; López, F.; Botrel, J.-F. (eds.), Historia de la edición y de la lectura en España, 1472-1914. Madrid: Fundación Germán Sánchez Rupérez, 619-632.

Buigues, (2003). La sociedad de los autores, Evolución global de la producción y Los lectores: oficios, profesiones y estados, en Infantes, V.; López, F.; Botrel, J.-F. (eds.), Historia de la edición y de la lectura en España, 1472-1914. Madrid: Fundación Germán Sánchez Rupérez, 292-302, 303-316 y 423-433.

Chartier, R. (1996). El orden de los libros. Lectores, autores, bibliotecas en Europa entre los siglos XIV y XVIII. Madrid: Gedisa.

Congreso de los Diputados (2017). “Membrado, Ramón”, Archivo Histórico de Diputados (1810-1977)

$<$ www.congreso.es/portal/page/portal/Congreso/Congreso/Diputados/ArchivoHDi> [Consulta: 15/11/2017].

Diario de las Sesiones de Córtes. Congreso de los Diputados. Legislatura de 1844 a 1845 (1876). T. I. Madrid, Imprenta y Fundición de la Viuda e Hijos de J. Antonio García, en Congreso de los Diputados, Diario de Sesiones. Serie Histórica, $<$ hwww.congreso.es/est_sesiones/> [Consulta: 15/11/2017].

Egercicios literarios que ofrecen al público los discípulos del P. Bañolas de San Blas, maestro de Gramática y Retórica en las Escuelas Pías de Alcañiz... (junio 1818). Zaragoza: en la Imprenta de Andrés Sebastián.

Egido, T. (2013). Obras y obritas de devoción, en Infantes, V.; López, F.; Botrel, J.-F. (eds.), Historia de la edición y de la lectura en España, 1472-1914. Madrid: Fundación Germán Sánchez Rupérez, 415-422.

Felipe de la Virgen del Carmen (1828). El Párroco. Pláticas doctrinales y morales para todos los domingos y fiestas principales del año, acomodadas al Evangelio del día para uso de los señores párrocos... T. I. Zaragoza: en la Imprenta de Francisco Magallón.

García Bascuñana, J. F. (2015). Lecturas españolas del Telémaco de Fénelon en los siglos XVIII yXIX, en Gimeno Puyol, M.D.; Viamonte Lucientes, E. (coords.), Los viajes de la Razón. Estudios dieciochistas en homenaje a María-Dolores Albiac Blanco. Zaragoza: Institución Fernando el Católico, 275-289.

García Cuadrado, A. (2000). La edición española del Compendio de la Historia de España de Duchesne: una traducción del Padre Isla. Revista General de Información y Documentación, 10 (2), 105-134.

Gilmont, J.-F. (2016). The Reformation and the Book. s. l., Routledge: ebook. 
Gimeno Puyol, M.D. (2017). Real Seminario de Nobles de Madrid (1725-1836), en Diccionario de la historia de la enseñanza del francés en España (siglos XVI-XX) (DiHEFE), García Bascuñana; J.F. (coord.), URV, $<$ www.grelinap.recerca.urv.cat/projectes/diccionario-historia-ensenanza-francesespana> [Consulta: 15/11/2017].

Índice último de los libros prohibidos y mandados expurgar (1790). Madrid: en la Imprenta de don Antonio Sancha.

Larriba, E. (2003). El público de la prensa, en Infantes, V.; López, F.; Botrel, J.-F. (eds.), Historia de la edición y de la lectura en España, 1472-1914. Madrid: Fundación Germán Sánchez Rupérez, 463-470.

Lopez, F. (2003). Los editores y Los clásicos del pueblo, en Infantes, V.; López, F.; Botrel, J.-F. (eds.), Historia de la edición y de la lectura en España, 1472-1914. Madrid: Fundación Germán Sánchez Rupérez, 358-367, 471-480.

Madoz, P. (1846). Belmonte, en Diccionario geográfico-estadístico de España y sus posesiones de ultramar. T. IV. Madrid: Establecimiento Literario-Tipográfico de P. Madoz y L. Sagasti, pp. 132-133.

Martínez Martín, J. A. (1991). Lecturas y lectores en el Madrid del siglo XIX. Madrid: CSIC.

Mur Gimeno, R. (1990). Sadurija. Anales secretos de la casa Membrado. Alcañiz: CESBA.

— (s. d.). Biblioteca del cura Membrado. Bellmunt de Mesquí, inventario manuscrito.

- (s. d.). Biblioteca de Juan Pío Membrado. Bellmunt de Mesquí, inventario manuscrito.

Sánchez Mariana, M. (1993). Bibliófilos españoles. Desde sus orígenes hasta los albores del siglo XX. Madrid: Biblioteca Nacional, Ministerio de Cultura, Ollero \& Ramos, Editores.

Vicente, G. (2016). 1808-1845. El final de la Universidad del Antiguo Régimen, en Lomba, C.; Rújula, P. (eds.), Historia de la Universidad de Zaragoza. Zaragoza: Prensas de la Universidad de Zaragoza, 166-210.

Vidiella, S. (1909). Calanda y Foz-Calanda. Boletín de Historia y Geografía del Bajo Aragón, 3, 240-251.

Viñao Frago, A. (2003). Textos escolares y didácticos, en Infantes, V.; López, F.; Botrel, J.F. (eds.), Historia de la edición y de la lectura en España, 1472-1914. Madrid: Fundación Germán Sánchez Rupérez, 400-407. 